\title{
Complete mitochondrial genome sequence of Labriocimbex sinicus, a new genus and new species of Cimbicidae (Hymenoptera) from China
}

\author{
Yuchen Yan ${ }^{1}$, Gengyun Niu ${ }^{2}$, Yaoyao Zhang ${ }^{1}$, Qianying Ren ${ }^{1}$, Shiyu Du ${ }^{1}$, Bocheng Lan ${ }^{1}$, Meicai Wei ${ }^{\text {Corresp. } 2}$ \\ ${ }^{1}$ Lab of Insect Systematics and Evolutionary Biology, Key Laboratory of Cultivation and Protection for Non-Wood Forest Trees, Central South University of \\ Forestry and Technology, Changsha, Hunan, China \\ 2 Jiangxi Normal University, Nanchang, Jiangxi, China \\ Corresponding Author: Meicai Wei \\ Email address: weim@jxnu.edu.cn
}

Labriocimbex sinicus Yan \& Wei gen. et sp. nov. of Cimbicidae is described. The new genus is similar to Praia Andre and Trichiosoma Leach. A key to extant Holarctic genera of Cimbicinae is provided. To identify the phylogenetic placement of Cimbicidae, the mitochondrial genome of $L$. sinicus was annotated and characterized using highthroughput sequencing data. The complete mitochondrial genome of $L$. sinicus was obtained with a length of 15,405 bp (GenBank: MH136623 ; SRA: SRR8270383) and a typical set of 37 genes (22 tRNAs, 13 PCGs, and two rRNAs). The results demonstrated that all PCGs were initiated by ATN codon, and ended with TAA or T stop codons. The study reveals that all tRNA genes have a typical clover-leaf secondary structure, except for trnS1. Remarkably, the secondary structures of the $r r n S$ and $r r n L$ of $L$. sinicus were much different from those of Corynis lateralis. Phylogenetic analyses verified the monophyly and positions of the three Cimbicidae species within the superfamily Tenthredinoidea and demonstrated a relationship as (Tenthredinidae + Cimbicidae) + (Argidae + Pergidae) with strong nodal supports. Furthermore, we found that the generic relationships of Cimbicidae revealed by the phylogenetic analyses based on $\mathrm{COI}$ genes agree quite closely with the systematic arrangement of the genera based on the morphological characters.

Phylogenetic tree based on two methods shows that $L$. sinicus is the sister group of Praia with high support values. We suggest that Labriocimbex belongs to the tribe Trichiosomini of Cimbicinae based on adult morphology and molecular data. Besides, we suggest to promote the subgenus Asitrichiosoma to be a valid genus. 
1 Complete mitochondrial genome sequence of Labriocimbex sinicus, a 2 new genus and new species of Cimbicidae (Hymenoptera) from

\section{China}

4

5 Yuchen Yan ${ }^{1}$, Gengyun Niu ${ }^{2}$, Yaoyao Zhang ${ }^{1}$, Qianying Ren ${ }^{1}$, Shiyu $\mathrm{Du}^{1}$, Bocheng Lan ${ }^{1}$, Meicai $6 \mathrm{Wei}^{2}$

7

$8 \quad{ }^{1}$ Lab of Insect Systematics and Evolutionary Biology; Key Laboratory of Cultivation and

9 Protection for Non-Wood Forest Trees, Central South University of Forestry and Technology, 10 Changsha, 410018, China.

112 Jiangxi Normal University, Nanchang, Jiangxi, China

12

Corresponding Author:

14 Meicai $\mathrm{Wei}^{2}$

1599 Ziyang Road, Nanchang, Jiangxi 330022, China

16 Email address: Email address: weim@jxnu.edu.cn 
42

43

44

45

46

47

48

49

50

51

52

53

54

55

56

57

58

59

60

61

62

63

64

65

66

67

68

69

70

71

72

73

74

75

76

77

78

79

80

81

\section{Abstract:}

Labriocimbex sinicus Yan \& Wei gen. et sp. nov. of Cimbicidae is described. The new genus is similar to Praia Andre and Trichiosoma Leach. A key to extant Holarctic genera of Cimbicinae is provided. To identify the phylogenetic placement of Cimbicidae, the mitochondrial genome of L. sinicus was annotated and characterized using high-throughput sequencing data. The complete mitochondrial genome of $L$. sinicus was obtained with a length of 15,405 bp (GenBank: MH136623; SRA: SRR8270383) and a typical set of 37 genes (22 tRNAs, 13 PCGs, and two rRNAs). The results demonstrated that all PCGs were initiated by ATN codon, and ended with TAA or T stop codons. The study reveals that all tRNA genes have a typical clover-leaf secondary structure, except for trnS1. Remarkably, the secondary structures of the $r r n S$ and $r r n L$ of L. sinicus were much different from those of Corynis lateralis. Phylogenetic analyses verified the monophyly and positions of the three Cimbicidae species within the superfamily Tenthredinoidea and demonstrated a relationship as (Tenthredinidae + Cimbicidae $)+($ Argidae + Pergidae) with strong nodal supports. Furthermore, we found that the generic relationships of Cimbicidae revealed by the phylogenetic analyses based on COI genes agree quite closely with the systematic arrangement of the genera based on the morphological characters. Phylogenetic tree based on two methods shows that L. sinicus is the sister group of Praia with high support values. We suggest that Labriocimbex belongs to the tribe Trichiosomini of Cimbicinae based on adult morphology and molecular data. Besides, we suggest to promote the subgenus Asitrichiosoma to be a valid genus.

\section{INTRODUCTION}

Hymenoptera is one of the largest insect order including more than 153,000 species which possess very diverse life strategies (Peters et al., 2017). Currently, complete or nearly complete mitochondrial genomes have been reported for 269 hymenopteran species (NCBI, May 2019). The Cimbicidae is a small family of the superfamily Tenthredinoidea from the phytophagous Symphyta, with about 197 valid species and 26 genera around the world. Within China, 63 species representing 13 genera have already been recorded (Taeger et al., 2010; Yan and Wei, 2010; Blank et al., 2012; Yan and Wei, 2013; Yan et al., 2014; Yan and Wei, 2016; Yan et al., 2018). The monophyly of Tenthredinoidea is supported by both morphological (Wei and Nie, 1997) and molecular data (Malm and Nyman, 2015) as well as both combined (Ronquist et al., 2012; Sharkey et al. 2012; Klopfstein et al., 2013). However, the relationships among core tenthredinoids are unclear. Cimbicidae was inferred as the sister to Argidae + Pergidae proposed by morphological analyses (Wei and Nie, 1997; Vilhelmsen, 2001; 2015; 2018). The disaccord with several recent studies may be caused by the limited dataset of Cimbicidae, by molecular or combined analyses, which have placed Cimbicidae as sister to Diprionidae (Schulmeister, 2003; Schmidt and Walter, 2014; Isaka and Sato, 2015; Malm and Nyman, 2015) or a clade including Diprionidae form a monophylum as sister to the remaining tenthredinoids (Heraty et al., 2011; Ronquist et al., 2012; Klopfstein et al., 2013).The monophyly of Cimbicidae has never been 
82 contested and not comprehensively tested until Vilhelmsen (2019). Adult Cimbicidae are

83 primarily characterized by their clubbed antennae, one or more of the apical antennomeres being 84 expanded. They vary in size from small $(6 \mathrm{~mm})$ to very large insects $(30 \mathrm{~mm})$, making them the 85 largest true sawflies known (Vilhelmsen, 2019). Some of the species are economically important 86 pests causing serious defoliation of woody plants such as elm (Ulmus, Ulmaceae), willow (Salix, 87 Salicaceae), honeysuckle (Lonicera, Caprifoliaceae) and cherry (Prunus, Rosaceae) (Gauld and 88 Bolton 1988). Malaise (1934) established the classification of Cimbicidae: subfamily, tribe, 89 subtribe and genus. Benson (1938) carried out a comprehensive study of sawflies, especially the 90 91 92 93 members of Cimbicidae, which was further determined by the classification status of Cimbicidae. It included four subfamilies: Abiinae, Cimbicinae, Pachylostictinae and Corynidinae. The Cimbicinae is the most diverse subfamily, it was divided into Cimbicini and Trichiosomini (Abe and Smith, 1991). The monophyly of Cimbicini was not supported by a following cladistic analyses with sufficient representation of cimbicid taxa of China (Deng, 2000) and a cladistic analyses with most representatives of cimbicid taxa of world (Vilhelmsen, 2019). The monophyly of Trichiosomini was supported by a cladistic analyses with sufficient representation of cimbicid taxa of China (Deng, 2000). The clade Abiinae + Cimbicinae received strong support in Vilhelmsen (2019).

Vilhelmsen (2019) placed Labriocimbex into Cimbicinae but the name is a nomina nudum.

So far, mitochondrial genome of two species in the family, Trichiosoma anthracinum (KT921411) and Corynis lateralis (KY063728) have been reported (Song et al. 2016; Doğan and Korkmaz, 2017). Here, we reported one complete mitochondrial genome of Labriocimbex sinicus. We also compared it with the previously reported mitochondrial genomes of $T$. anthracinum and $C$. lateralis for better understanding of the mitochondrial genome characteristics of the Cimbicidae. Finally, we have performed phylogenetic analyses to confirm the sister group relation of Labriocimbex and to clarify the systematic position of Cimbicidae within Symphyta.

\section{MATERIALS \& METHODS}

\section{Description of new species}

Specimens were examined with a Leica S8APO dissection microscope. Adult images were taken with a Nikon D700 digital camera and a series of images edited using Helicon Focus (HeliconSoft), while detailed images were taken with Leica Z16 APO/DFC550. A cylinder of semitransparent plastic was placed around the specimen to disperse the light, that methods follows Vilhelmsen (2019). The specimen must be sufficiently relaxed in a moist chamber before dissection. Dissected ovipositor valves, gonoforcep and penis valves were permanently mounted on slides in gum Arabic and images produced and composited automatically with a Nikon CiL/DS-Fi3. We used Adobe Photoshop CS 6.0 for further image processing. The terminology of sawfly genitalia follows Ross (1945), and that of general morphology follows Viitasaari (2002). For a few terms (e.g. middle fovea and lateral fovea), we followed Takeuchi (1952). Abbreviations used were: $\mathrm{OOL}=$ distance between the eye and outer edge of lateral ocelli; POL 
$122=$ distance between the mesal edges of the lateral ocelli; OCL $=$ distance between a lateral

123 ocellus and the occipital carina or hind margin of the head.

124 The holotype and some paratypes of the new species are deposited in the Asian Sawfly

125 Collection, Nanchang, China (ASCN). The most remaining paratypes are deposited in the Insect

126 Collection of Central South University of Forestry and Technology, Changsha, Hunan, China

127 (CSCS). A few paratypes are kept in Lishui Academy of Forestry (LSAF).

128 The electronic version of this article in Portable Document Format (PDF) will represent a

129 published work according to the International Commission on Zoological Nomenclature (ICZN),

130 and hence the new names contained in the electronic version are effectively published under that

131 Code from the electronic edition alone. This published work and the nomenclatural acts it

132 contains have been registered in ZooBank, the online registration system for the ICZN. The

133 ZooBank LSIDs (Life Science Identifiers) can be resolved and the associated information viewed

134 through any standard web browser by appending the LSID to the prefix http://zoobank.org/. The

135 LSID for this publication is: urn: 1sid: zoobank.org: pub: EE7F5193-78B2-42CE-87C1-

136 B3FE947CB70F. The online version of this work is archived and available from the following

137 digital repositories: PeerJ, PubMed Central and CLOCKSS.

138

139

140

141

142

143

144

145

146

147

148

149

150

151

152

153

154

155

156

157

158

159

160

161

162

163

\section{DNA library construction and sequencing}

Total DNA was extracted from L. sinicus using an E.Z.N.A. ${ }^{\circledR}$ Tissue DNA Kit (Omega, Norcross, GA) and was stored at $-20^{\circ} \mathrm{C}$, in accordance with the manufacturer's instructions. Sequencing libraries with approximately 250-bp insertions were constructed using a NEXT flex $^{\mathrm{TM}}$ Rapid DNA-Seq Kit (Illumina, San Diego, CA) in accordance with the manufacturer's protocol. Each library was sequenced using an Illumina Hiseq 4,000 to generate 150-bp paired end reads at BGI-Shenzhen, China. The sequencing reads have been deposited in NCBI SRA database under accession number: PRJNA507477.

\section{Mitochondrial genome assembly}

Next generation sequencing and bioinformatic analyses were performed by Shanghai Majorbio Bio-pharm Technology Co., Ltd. Reconstruction of the mitochondrial genome from Illumina reads was carried out using three different approaches to ensure the accuracy of the assemblies: SOAPdenovo v2.0 (Luo et al., 2012), MITObim v1.8 (Hahn et al., 2013) and NOVOPlasty v2.7.1 (Dierckxsens et al., 2017). The assembled mitochondrial fragments were identified using BlastX and $T$. anthracinum (NC029733) mitochondrial genes as queries. Prediction and annotation of protein-coding, tRNA and rRNA genes were performed using DOGMA (http://dogma.ccbb.utexas.edu/) or MITOS (http://mitos.bioinf.uni-leipzig.de/index.py) with annotation from a reference mitochondrial genome. Queries were then corrected manually.

\section{Mitochondrial genome annotation and secondary structure prediction}

All RNA genes were identified by employing the online MITOS tool (http://mitos.bioinf.unileipzig.de/index.py) (Bernt et al., 2013) with the invertebrate mitochondrial genetic code. The initiation and termination codons of PCGs were determined using Geneious v11.0.3 (http://www.geneious.com) with reference sequences from other symphytan species with 
164

165

166

167

168

169

170

171

172

173

174

175

176

177

178

179

180

181

182

183

184

185

186

187

188

189

190

191

192

193

194

195

196

197

198

199

200

201

202

203

subsequent manual adjustment. The $\mathrm{A}+\mathrm{T}$ content of nucleotide sequences and relative synonymous codon usage (RSCU) were calculated using MEGA v7.0 (Kumar et al., 2016). Strand asymmetry was calculated using the formulae (Perna and Kocher, 1995): GC-skew $=(G-C) /(G$ $+\mathrm{C})$ and $\mathrm{AT}-$-skew $=(\mathrm{A}-\mathrm{T}) /(\mathrm{A}+\mathrm{T})$, for the strand encoding the majority of the PCGs.

The secondary structures of the $r r n S$ and $r r n L$ were partitioned into four areas and six areas, respectively. The secondary structures of rRNAs were inferred using alignment to models predicted for $T$. anthracinum. First, the primary sequence and the secondary structure of this species were aligned in MARNA (Siebert and Backofen, 2005) to identify a consensus sequence as well as a consensus structure in the output files. Secondly, the secondary structures of the $r r n S$ and $r r n L$ in L. sinicus were predicted by specific structure models in SSU-ALIGN (Nawrocki, 2009). Finally, the structures were artificially transformed to their relative secondary structure with micro changes.

The predicted secondary structures of RNAs were drawn using VARNA v3-93 (Darty et al., 2009) and RNAviz 2.0.3 (De Rijk et al., 2003). Helix numbering was performed following the Apis mellifera rRNA secondary structure (Gillespie et al., 2006) including minor modifications.

\section{Taxon sampling}

We sampled all known mitochondrial genomes representatives from the symphytan of Hymenoptera (34 species of Symphyta and two representatives of Apocrita) and four Nonhymenopteran outgroups (Mecoptera, Diptera, Megaloptera, Coleoptera) including some mitochondrial genomes downloaded from GenBank which had previously been sequenced, and the newly sequenced mitochondrial genome in this study (Table 1).

To investigate the phylogenetic relationship of Labriocimbex within Cimbicidae, we used 40 species (43 samples) of seven genera belonging to three subfamilies according the classification system of Abe \& Smith (1991), by using partial cytochrome oxidase subunit I (COI) gene of mitochondrial genome. Composite of ingroup and outgroup taxon, as indicated in Table 2, were developed by sequences from different taxon either from our own sequences or those deposited in GenBank.

\section{DNA extraction, Polymerase chain reaction (PCR) and sequencing of $\mathrm{COI}$ gene}

Total genomic DNA was extracted from muscles or single leg of adult specimens stored in ethanol at $-20^{\circ} \mathrm{C}$ using the DNeasy Blood \& Tissue Kit (Qiagen, Hilden, Germany). PCRs $(50 \mu 1)$ contained $25 \mu 1$ Taq MasterMix (CW0682M) reaction buffer, $2 \mu 1$ of each primer, $2 \mu 1$ DNA template and $19 \mu 1$ PCR grade $\mathrm{H} 2 \mathrm{O}$. The PCR programme consisted of an initial denaturing step at $95^{\circ} \mathrm{C}$ for one min, followed by 42 cycles of $20 \mathrm{~s}$ denaturing at $95^{\circ} \mathrm{C}, 30 \mathrm{~s}$ annealing at 55 ${ }^{\circ} \mathrm{C}$ and $80 \mathrm{~s}$ extension at $68{ }^{\circ} \mathrm{C}$; the last cycle was followed by a final 7 min extension step at 68 ${ }^{\circ} \mathrm{C}$. The primers of COI referenced Nyman et al (2006). Purified PCR products were sequenced in both directions with the BigDye v3.1 Mix Sequencing Kit (Applied Biosystems) and an ABI $3730 \mathrm{XL}$ automated sequencer (Applied Biosystems). Sequence trace files were read and edited using Sequencher v4.8 (BGI-Shenzhen cop, China). 
204 COI gene sequences were checked and assembled in Geneious v11.0.3

205 (http://www.geneious.com), prior to submission to GenBank (accession numbers MN076590-

206 MN076605).

207

208

209

\section{Phylogenetic analysis}

We used the Maximum Likelihood (ML) and Bayesian Inference (BI) methods to construct

210

211

212

213

214

215

216

217

218

219

220

221

222

223

224

225

226

227

228

229

230

231

232

233

234

235

236

237

238

239

240

241

242

243 phylogenetic trees. A total of 13 PCGs were aligned by MUSCLE in MEGA v7.0 individually, two rRNAs and COI gene were aligned by MAFFT (https:/www.ebi.ac.uk/Tools/msa/mafft/) (Katoh \& Standley, 2013). Then, these (13 PCGs and two rRNAs) aligned nucleotide sequences were concatenated using SequenceMatrix v1.7.8 (Vaidya et al., 2011) and partitioned into several data blocks.

The partitioned data block file was used to infer both partition schemes and substitution models in PartitionFinder v1.1.1 (Lanfear et al., 2012), with "unlinked" branch lengths under the "greedy" search algorithm. The standard partitioning schemes "bic" and "aicc" were selected for BI and ML analyses, respectively. BI analyses were conducted with the GTR $+\mathrm{I}+\mathrm{G}$ model and $\mathrm{HKY}+\mathrm{G}$ model using MrBayes v3.2.2 (Ronquist et al., 2012). Four simultaneous Markov chains (three cold, one heated) were run for five million generations in two independent runs, with sampling every 1,000 generations and the first $25 \%$ of generations were discarded as burn-in.

The best partitioning scheme were chosen for 13 PCGs (Table 3). The best-fit model of nucleotide substitution and phylogenetic construction based on ML were created using the IQ-TREE web server (http://iqtree.cibiv.univie.ac.at/). The previous data block file was used as well as the original parameters. In addition, 0.1 was employed as the disturbance intensity and 1000 as the IQ-TREE stopping rule.

The COI gene phylogenetic construction also based on ML and BI analyses. All related files have been uploaded to Figshare (https://figshare.com/s/b7e5b401b4881328c3b1).

\section{RESULTS AND DISCUSSION}

\section{Description}

Labriocimbex Yan \& Wei, gen. nov. urn: 1sid: zoobank. org: act: 29EB6C0E-881D-46E2-AEF0-3BDF5992EC37

\section{Type species: Labriocimbex sinicus Yan \& Wei, sp. nov.}

Description. Body middle to large-sized; black, without metallic luster (Figure 1); head and thorax with dense and long yellowish brown hairs; clypeus distinctly broader than distance between lower margin of eyes, anterior margin with arcuate notch, furrow between clypeus and supraclypeal area deep (Figure 2A); base of labrum much broader than apex, lateral margin of labrum distinctly narrowed upward (Figure 2A); mandibles elongate, with three teeth in total, basal one truncate at apex (Figures 3A, 3B); maxillary palp with 6 palpomeres, apex 1-2 combined distinctly shorter than palpomere 4; labial palp with 4 palpomeres, short (Figure 
$2442 \mathrm{G}$ ); malar space 2.3 times the diameter of lateral ocellus, about as long as scape and pedicel 245 combined; eyes moderately large, inner margins parallel, distance between eyes slightly longer 246 than longest axis of eye (Figures 2A, 2B); lateral part of head distinctly dilated behind eyes in 247 lateral view (Figure 2B) and dorsal view (Figure 2D); postocellar area with median and lateral 248 furrows distinct, frontal carina indistinct (Figure 2D). Antenna longer than breadth of head, club 249 of antenna strongly enlarged with obscure annular suture, with 5 antennomeres before club, 250 antennomere 3 slender and distinctly longer than antennomeres 4 and 5 combined (Figure 2H).

251 Propleuron and sternum merged; median suture of mesonotum shallow, notaulus distinct; 252 mesoscutellum flat, anterior margin subtruncate, posterior margin roundly triangular (Figure 2E); 253 distance between inner margin of cenchri 3.3 times the longest axis of a cenchrus, distance 254 between outer margin of cenchri longer than breadth of mesoscutellum (Figure 2E). Coxae and 255 femur of leg with long hairs; ventral side of middle and hind femur without tooth near apex 256 (Figures 2F, 3C), hind coxae close to each other; inner spur of hind tibia as long as apical breadth 257 258 259 260 261

262

263

264

265

266

267

268

269

270

271

272

273

274

275

276

277

278

279

280

281

282 of tibia, apex blunt and membranous (Figure 3J), about 0.4 times length of metabasitarsus; metabasitarsus slightly shorter than tarsomeres 2 and 3 combined, base of hind tibia narrower than apex (Figure 2F); 1st and 2nd tarsal pulvilli long, nearly contiguous (Figure 2F); claw simple, roundly bent (Figure $3 \mathrm{~K}$ ). Fore wing with crossvein $2 \mathrm{r}$ present, base of vein Rs absent (Figure 1A); vein 2r-m and 2m-cu almost interstitial, pterostigma long and narrow; anal cell strongly narrowed in basal $1 / 3$ with a short anal crossvein, apical anal cell about 2 times the length of basal anal cell; cell Rs and M closed in hind wing, apex of anal cell quadrate, petiole of anal cell longer than length of vein cu-a, jugum region only with 1 longitudinal vein, without crossvein (Figure 1A). Sternites and basal abdominal terga with long hairs, posterior margin of abdominal tergum 1 shallowly incised, without middle carina and lateral carina (Figures 2E, 2F). Genital plate of female developed with wide incision and arcuate in middle (Figure 3L); apical ovipositor sheath short and roundish in lateral view (Figure 3D), tapering toward apes in dorsal view (Figure 3F); apex of lancet and lance curved upwards (Figures 3M, 3N), each annulus with 1 pore, serrulae sub-truncate at apex, lateral teeth sharp (Figure 3G). Each sternite of male incised in middle, both sides roundish (Figure 3E); penis valve broad, with apical lobe bulge, ventral hook small, lateral ridge distinct (Figure 3H); harpe small, longer than broad (Figure 3I). Etymology. The generic name is composed of "labrio-" and "-cimbex", emphasizing the shape of labrum differs from other genera of the family. Gender masculine.

Distribution. China.

Host plant: Prunus pseudocerasus of Rosaceae (Female adult were observed laying eggs on it). Remarks.

The name Labriocimbex was mentioned in two papers before (Li \& Wu, 2010; Vilhelmsen, 2019). The name is a nomina nuda in these papers as it was not accompanied by a proper description and type designation. The name was originally proposed by the senior author of this paper (MW) for the genus hear described as new to science. The present paper constitutes the proper establishment of the name. 
283 This new genus is similar to Praia Andre and Trichiosoma Leach. It is similar to Praia having 284 the head and thorax with dense and long hairs; the antenna with 5 antennomeres before the club; 285 the coxae and femur of leg with long hairs; the ventral side of hind femur without a denticle near 286 apex; the base of hind tibia narrower than apex; the 1st and 2nd tarsal pulvilli long. It differs 287 from Praia by having the triangular labrum, the base of labrum much wider than its apex and the 288 basal breadth about half the breadth of clypeus; the inner margins of eyes parallel; the anal cell 289 strongly narrowed in basal $1 / 3$ with a short crossvein and apical anal cell about 2 times the length 290 of basal anal cell; the abdomen all black, without transverse band. It differs from Trichiosoma by

291

292

293

294

295

296

297

298

299

300

301

302

303

304

305

306

307

308

309

310

311

312

313

314

315

316

317

318

319

320

321 the ventral side of the hind femur without a subapical denticle; the 1st and 2nd tarsal pulvilli in the male very long and nearly contacting to each other, and the different pattern of the male genitalia.

Trichiosomini includes 3 genera: Trichiosoma, Pseudoclavellaria and Leptocimbex (Abe \& Smith, 1991; Deng, 2000). Most of the characteristics of the new genus suggest placing it in the tribe Trichiosomini. The most important characteristics include: the labrum large with the basal breadth about half the breadth of clypeus, the jugum region in hind wing without crossvein, the clypeus very short and much broader than lower distance between eyes and not merging with supraclypeal area. See the key below for the relationship of the new genus and other genera of the family.

\section{Key to extant Holarctic genera of Cimbicinae}

1 Anal cell of fore wing divided into two by a long medial constriction; clypeus not enlarged, distinctly narrower than distance between lower corners of eyes, or antennae with 5 antennomeres and nearly as long as head breadth; inner margins of eyes strongly convergent or strongly divergent downward.

-- Anal cell of fore wing divided into two near the middle by a straight vein or at least touching in the middle (rarely); clypeus distinctly broader than distance between lower corners of eyes; antennae at least with 6 antennomeres (except for Pseudoclavellaria) and distinctly longer than head breadth; inner margin of eyes subparallel or slightly convergent downward Cimbicinae. 3

2 Inner margins of eyes strongly convergent downward; distance between antennal toruli about 2 times as long as breadth of clypeus, clypeus not separated from supraclypeal area by epistomal sulcus; anterior tentorial small and shallow; head narrowed behind eyes in dorsal view, POL longer than OCL; hind orbit with distinct occipital carina; mesonotum with notauli between mesoscutal lateral lobe and middle lobe almost obsolete; hind coxae separated, apex of tibial spur acute and sclerotized. Corynidinae. Corynis Thunberg -- Inner margins of eyes strongly divergent downward; distance between antennal toruli about as long as breadth of clypeus, clypeus separated from supraclypeal area by a distinct transversal furrow; anterior tentorial large and deep; head enlarged behind eyes in dorsal view, POL much shorter than OCL; hind orbit round, without occipital carina; mesonotum with notauli between 
mesoscutal lateral lobe and middle lobe deep; hind coxae contiguous, apex of tibial spur blunt and membranous.

Abiinae

3 Labrum small, clearly narrower than 1/4 breadth of clypeus; clypeus narrower than lower distance between eyes, or clypeus triangularly convex and merging with supraclypeal area........4

-- Labrum large, not narrower than 1/3 breadth of clypeus; jugum region in hind wing without crossvein; clypeus very short and much broader than lower distance between eyes, not merging with supraclypeal area.

4 Jugum region in hind wing without crossvein; ventral side of middle and hind femora with 1- 2 rows of denticles, or anal cell in fore wing with a punctiform middle petiole, or head narrowed behind eyes in dorsal view.

-- Jugum region in hind wing with a crossvein; middle and hind femora without denticle ventrally; anal cell of fore wing with a middle crossvein; head not narrowed behind eyes in dorsal view; Clypeus and supraclypeal area not entirely merging together and with a shallow depression between them; distance between antennal toruli and posterior margin of head about as long as distance between toruli and anterior margin of clypeus; postocellar area about as long as broad. Cimbex Olivier

5 Outer side of middle and hind coxae with a large denticle; ventral side of hind femur with 1-2 rows of denticles; mandibles simple, without inner tooth; malar space very long, clearly longer than antennomere 4; antennae with 8-9 antennomeres [claw simple].......Odontocimbex Malaise

-- Outer side of coxae without denticle; ventral side of femora without 1-2 rows of denticles; mandibles with distinct inner tooth; malar space short, at most as long as antennomere 1, much shorter than antennomere 4; antennae with 6-7 antennomeres.

6 Clypeus clearly narrower than shortest distance between eyes and separated from supraclypeal area by a shallow but distinct furrow; anal cell in fore wing with a short petiole at basal third; claw simple; tibial spur stout, much shorter than apical breadth of tibia, apex obtuse; head enlarged behind eyes in dorsal view.

Praia Andre

-- Clypeus clearly broader than shortest distance between eyes and merging with supraclypeal area, furrow between them absent; anal cell in fore wing with a distinct crossvein at basal fourth; claw bifurcate; tibial spur slender, clearly longer than apical breadth of tibia, tapering toward apex; head narrowed behind eyes in dorsal view.

Agenocimbex Rohwer

7 Ventral side of middle and hind femur with distinct denticle near apex [clypeus and labrum black; labrum narrowed toward base.

Trichiosoma Leach

-- Ventral side of femur without denticle.....

8 Head and thorax with dense and long hairs; club of antennae not segmented; abdominal tergum 1 without lateral carina; tarsal pulvilli large, 1 st and 2 nd pulvilli nearly touching to each other, first pulvillus longer than 1/2 length of basitarsus; apical anal cell of forewing 1 to 2 times length of basal anal cell.................................................................. 9

-- Head and thorax without dense and long hairs; club of antennae distinctly segmented; abdominal tergum 1 at least with distinct lateral carina at basal 1/2; tarsal pulvilli short and small, separated 
362

363

364

365

366

367

368

369

370

371

372

373

374

375

376

377

378

379

380

381

382

383

384

385

386

387

388

389

390

391

392

393

394

395

396

397

398

399

400

401

each other, distance between basal 2 pulvilli not shorter than length of a pulvillus, first pulvillus much shorter than half length of basitarsus; fore wing with apical anal cell about 3 times length of basal anal cell.......................................................................eptocimbex Semenov

9 Labrum broadened toward base and distinctly narrowed toward apex; antennae with 6 antennomeres; inner spur of hind tibia as long as apical breadth of tibia; abdominal terga with long hairs; fore wing with apical anal cell 2 times as long as basal anal cell, vein $2 \mathrm{~m}$-cu almost interstitial to vein 1r-m; clypeus and labrum black..........Labriocimbex Yan and Wei, gen. nov.

-- Labrum clearly narrowed toward base and distinctly broadened toward apex; antennae with 5 antennomeres; inner spur of hind tibia clearly shorter than apical breadth of tibia; abdominal terga without long hairs; forewing with apical anal cell as long as basal anal cell, vein $2 \mathrm{~m}-\mathrm{cu}$ remote from vein 1r-m; clypeus and labrum white.

Pseudoclavellaria Schulz

\section{Labriocimbex sinicus Yan \& Wei sp. nov. (Figures 1-3)}

urn: 1sid:zoobank.org:act:E1454ED2-5321-4D39-97C2-EC8957D034C1

Female. (Holotype) Body length $21 \mathrm{~mm}$ (Figure 1A). Black; apical 1/2 of mandible reddish brown (Figures 3A, 3B); inner and ventral side of club of antennae largely brown, outer side dark brown (Figure $2 \mathrm{H}$ ); cenchri pale yellowish white; posterior half of mesepimeron, metapleuron largely, metanotum except for a small macula behind cenchri and most of metapostnotum, median triangular macula and narrow posterior margin of abdominal tergum 1 (Figure 2E) yellowish white; apex of each tibia, tarsus and claw reddish brown, tarsal pulvillus grayish white (Figure 2F). Wings brownish hyaline, stigma black, basal 3/5 of vein $\mathrm{C}$ in fore wing, basal 3/7 of vein $\mathrm{Sc}+\mathrm{R}$ and entire vein $\mathrm{M}+\mathrm{Cu}$ pale yellow, vein A pale brown, other veins largely black, vein $\mathrm{J}$ and basal parts of all other veins in hind wing pale yellow (Figure 1A). Hairs on face and gena black at base and yellowish white at apex (Figure 2A); hairs on vertex of head and mesonotum black (Figure 2D); hairs on pronotum and scutellum yellowish white largely except for black basal 0.2 ; hairs on mesopleuron, coxae and femora yellowish brown largely with less than basal 0.3 black (Figures 2C, 2E, 2F); inner hairs of fore tibia reddish yellow; abdominal terga 1-2 and posterior margins of terga 3-4 with yellowish white hairs; hairs on ventral side of terga and sternites $1-3$ black in basal 0.4 and reddish yellow in apical 0.6.

Body densely microsculptured, matt; lower margin of orbit, small fovea lateral to lateral ocellus, apical half of mandible, narrow lateral side of mesoscutal lateral lobe, ventral part of trochanters and of femora distinctly shiny, ventral half of mesepisternum feebly microsculptured mixed with some minute punctures, shiny; venter of abdomen feebly shiny.

Apex of labrum thickened with middle notch (Figure 2A); median fovea round and deep, lateral foveae obscure (Figure 2D); middle of frons concave, lateral furrow of frons shallow; postocellar furrow distinct, interocellar furrow long and deep; postocellar area quadrate, middle furrow very shallow, indistinct; lateral furrows shallow, weakly divergent backwards (Figure 2D). Long hairs on gena clearly shorter than $1 / 3$ head width in dorsal view. Club of antennae as long as length of antennomeres 4 and 5 combined, with obscure annular suture (Figure 2H). Mesopleuron without

Peer] reviewing PDF | (2019:01:34672:4:0:NEW 3 Sep 2019) 
402 middle oblique ridge (Figure 2C); cenchrus 2.1 times broader than long, reniform (Figure 2E).

403 Coxae and femora with dense hairs longer than breadth of femora (Figure 2F); inner hairs of tibia 404 dense and short (Figure 2F). Vein 2r in fore wing joining cell 2Rs at basal 0.4; cu-a joining cell $4051 \mathrm{M}$ close to vein 1M (Figure 1A). Abdominal terga 1-2 and posterior margin of terga 3-4 with 406 dense and long hairs, other terga with sparse and short hairs. Sternites and ventral side of 407 abdominal terga with spare and long hairs (Figure 2F). Ovipositor sheath 0.8 times as long as 408 metatarsomere 1 and 2 combined, apical margin roundish in lateral view (Figure 3D), acute at 409 apex in dorsal view (Figure 3F). Lancet with 45 serrulae (Figure 3N), middle serrulae as Figure $4103 \mathrm{G}$, annular spine bands narrow, membranous area between serrulae roundly protruding, middle 411 serrulae subtruncate at apex, with 5-6 proximal and 4-5 distal subbasal teeth (Figure 3G).

412 Male: Body length $21.5 \mathrm{~mm}$ (Figure 1B); body color and structure similar to female except for 413 following parts: labrum broad and large; anterior margin of clypeus arc-shape, without incision; 414 metathorax and abdominal tergum 1 entire black; subgenital plate slightly broader than long 415 (Figure 3E), apical margin round; apex of each sternite with clear middle incision, both sides 416 roundly arcuate. Penis valve shown in Figure 3H, gonoforcep shown in Figure 3I.

417 Holotype. Female (CSCS13010_Lab001). China: Hunan Province, Wugang County, Mt. Yun, 418 Yunfengge alt. 1,380 m, 26³8.630' N, 110³7.299' E, April 13, 2013, Zejian Li leg.

419 Paratypes: 17 Females, 15 Males (CSCS13010_Lab002-033). Collecting information as the 420 holotype. 18 Females, 10 Males (CSCS13015_Lab034-061), locality and collector as the 421 holotype, April 15, 2013. 45 Females, 17 Males (CSCS13014_Lab062-123), locality and 422 collecting time as the holotype, Liwei Qi, Biao Chu leg. 36 Females, 51 Males 423 (CSCS11009_Lab124-210), China: Hunan Province, Wugang County, Mt. Yun, Shengli Temple, 424 alt. 1,145 m, 26³8.859' N, 110³7.026' E, April 18-22, 2011, Zejian Li, Liwei Qi leg. 17 Females, 42522 Males (CSCS05001_Lab211-249), China: Hunan Province, Wugang County, Mt. Yun, alt. 426 800-1,100 m, April 24-26, 2005, Meicai Wei, Shaobing Zhang, Wei Xiao leg. One Male 427 (CSCS1999001_Lab250), China: Hunan Province, Wugang County, Mt. Yun, alt. 1,300 m, April 428 3, 1999, Wei Xiao leg. Two Females, six Males (LSAF18029_Lab251-258), China: Zhejiang 429 Province, Lin'an City, Mt. Tianmu, alt. 1,506, $30.349^{\circ} \mathrm{N}, 119.424^{\circ} \mathrm{E}$, April 19, 2018, Zejian Li, 430 Mengmeng Liu leg. One Females (LSAF17053_Lab259), locality and collector as the former, 431 April 16, 2017. One Females, 26 males (LSAF17054_Lab259-285), locality as the former, April 432 17, 2017, Tingting Ji leg. Four Females, two Males (CSCS18006_Lab286-291), China: Hunan 433 Province, Wugang County, Mt. Yun, alt. 1,124 m, 26³8.059' N, 110³7.017' E, April 03, 2018, 434 Meicai Wei, Gengyun Niu, Hannan Wang leg. Seven Females, one Males (CSCS18007_Lab292435 299), locality as the former, alt. $1,129 \mathrm{~m}, 26^{\circ} 39.003^{\prime} \mathrm{N}, 110^{\circ} 37.027^{\prime} \mathrm{E}$, April 04, 2018, Meicai 436 Wei, Hannan Wang leg.

437 Variation. Body length 18-24 $\mathrm{mm}$ in female, 19-24 $\mathrm{mm}$ in male; club of antennae color brown to 438 pale yellowish brown; hairs color on pronotum and scutellum yellowish white to yellowish brown. 439 Distribution. China (Hunan, Zhejiang).

440 Etymology: The specific name of the new species refers to the distribution area, China.

441 Remarks. 
442 Labriocimbex pilosus sp. nov. (Li \& Wu, 2010) and Labriocimbex sinicus (Vilhelmsen, 2019)

443 were two nomina nuda and have never been properly described before this paper. The two

444 manuscript names were originally proposed by the senior author of this paper (MW) for the two

445 undescribed species found in China. The former species represents only by a few specimens

446 from different localities and so it is not described here, and specimen collection record: one

447 female, China, Gansu Province, Mt. Xiaolong, Maiji forest farm, Sun hill; alt. 1,620, 34²5'11.0

448 "N, 10546'30.1" E, April 17, 2009, Wu XingYu leg.

449 Labriocimbex sinicus Yan \& Wei, sp. nov. is similar to L. zaraeoides (Malaise, 1939) comb.

450 nov. (Figure 4A), but differs from the latter in the following characters: the clypeal notch deep,

451 depth about 1/2 length of clypeus; between the clypeus and supraclypeal area with a distinct

452 transverse furrow; the long hairs on gena 3.5 times as long as diameter of lateral ocellus, longer

453 than the shortest axis of an eye; the long hairs on mesopleuron about 4.5 times as long as

454 diameter of lateral ocellus; the abdominal tergum 1 largely black.

455

456

457

458

Labriocimbex zaraeoides (Malaise, 1939) comb. nov. (Figure 4)

Trichiosoma zaraeoides Malaise, 1939: 16-17.

459 Remarks. This species is similar to L. sinicus Yan \& Wei sp. nov., the majority of the characters

460 place it in the new genus Labriocimbex. The most important of these characters are: the broadly

461 emarginated clypeus, the triangular labrum (Figure 4C), the form of the antennae (antennae with

4625 antennomeres before the rigid club; joints of the club very indistinct [sic!] Malaise, 1939); the

463 slender hind legs (the coxae and femur of leg with long hairs; the ventral side of hind femur

464 without a denticle near apex; the base of hind tibia narrower than apex; the 1st and 2nd tarsal

465 pulvilli long, Figure 4D) the venation (the anal crossvein punctiform and the anal cell strongly

466 narrowed, Figure 4A); the color of body (the posterior half of mesepimeron, metapleuron,

467 metanotum and abdominal tergum 1 yellowish white, Figures 4B, 4D and 4G). The characters

468 that separate this species from all known Trichiosoma are the yellowish white color of the

469 metanotum and the base of the abdomen, and the ventral side of the hind femur without a large

470 denticle near apex. L. zaraeoides differs from L. sinicus in the following characters: the clypeal

471 notch shallow, depth about 1/4 length of clypeus; the transverse furrow between clypeus and

472 supraclypeal area absent (Figure 4C); the long hairs on gena 2.5 times the diameter of lateral

473 ocellus, shorter than the shortest axis of an eye (Figure 4E); the long hairs on mesopleuron about

4743.5 times as long as diameter of the lateral ocellus (Figure 4B); the abdominal tergum1 largely

475 yellow brown (Figure 4G).

476

477 General features of the $L$. sinicus mitochondrial genome

478 We sequenced the complete mitochondrial genome of L. sinicus (GenBank accession no.

479 MH136623), a typical set of 37 genes, including 13 PCGs, 22 tRNAs and two rRNAs. Most of

480 the genes were located on the J-strand except for four PCGs, two rRNAs and seven tRNAs

481 (Table 4).

Peer] reviewing PDF | (2019:01:34672:4:0:NEW 3 Sep 2019) 
482 A total of 14 pairs of genes were directly adjacent, without overlapping or intergenic nucleotides. 483 The total length of the intergenic regions was $268 \mathrm{bp}$ in 18 locations with a size ranging from 1 484 to $50 \mathrm{bp}$ (Table 4). The longest was located between trnH and ND4, while the second longest 485 was $45 \mathrm{bp}$ located between $r r n S$ and trnM. In comparison with the mitochondrial genome of $T$. 486 anthracinum and $C$. lateralis, there were differences in the length of intergenic spacers and 487 locations. The longest (414 bp) was located at the start of the mitochondrial genome before $\operatorname{trn} Y$ 488 in T. anthracinum. The longest length of the intergenic spacers was $345 \mathrm{bp}$ located between the $489 N D 6$ and $C Y T B$ genes in C. lateralis. We found that homologous searches on the longest

490

491

492

493

494

495

496

497

498

499

500

501

502

503

504

505

506

507

508

509

510

511

512

513

514

515

516

517

518

519

520

521

522 intergenic region of $L$. sinicus revealed substantial differences from any identified Symphyta sequence.

There were in total 32 overlapping nucleotides between neighboring genes in six locations, and the range of length of the overlapping sequence is from 3 to $14 \mathrm{bp}: \operatorname{trn} M$ and $\operatorname{trn} Q, A T P 8$ and ATP6, ND4 and ND4L, trnN and trnS2, and ATP6 and COIII; and the longest was 14 bp between ATP6 and COIII (Table 4). The common motifs such as: ATGATAA between ATP8 and ATP6, and ATGTTAA between ND4 and ND4L, which also exist in T. anthracinum, and are not found in C. lateralis, are common features of many other insect mitochondrial genomes (Song et al., 2016; Doğan and Korkmaz, 2017).

\section{Protein-coding genes and codon usage}

The mitochondrial genome of L. sinicus contains 13 PCGs, and its length is $12,456 \mathrm{bp}$, accounting for $80.86 \%$ of the total length (Table 5). All PCGs were initiated by ATN codons. All PCGs were ended with TAA as stop codon except for ND5 which ended with T (Table 4).

The codon usage of $L$. sinicus also shows a significant bias towards A/T Leu, Ile, Phe and Ser, were found as the most frequently used amino acids. TTA-Leu showed the highest RSCU of 5.04 (Table 6). Comparisons of the RSCU with those of $C$. lateralis and $T$. anthracinum showed a similar pattern for codon usage bias and reflected a significant correlation between codon preference and nucleotide composition, that is similar to other symphytan species (Dowton et al., 2009; Wei et al., 2010; 2015; Korkmaz et al., 2015, 2016, 2017; Song et al., 2015, 2016; Niu et al., 2019; Du et al., 2018; Ma et al., 2019; Tang et al., 2019). Codons rich in C and G, CGC-Arg and CTC-Leu was absent, CGG-Arg, GGC-Gly, AGC-Ser, ACG-Thr, CTG-Leu, GTC-Val, GTG-Val and TGC-Cys, were used once, AGG-Ser, TCG-Ser, TCC-Ser, CCG-Pro and GCGAla were rarely used, which is similar to both cimbicid mitochondrial genomes (Table 6). The ratio can be calculated by rate of $\mathrm{G}+\mathrm{C}$ rich codons (Pro, Ala, Arg, and Gly) and $\mathrm{A}+\mathrm{T}$ rich codons (Phe, Ile, Met, Tyr, Asn, and Lys), and it is 0.28 in L. sinicus, which is similar to those of other symphytan species (0.28-0.31) (Korkmaz et al., 2015). The translation, initiation, and termination signals as well as the codon usage of the L. sinicus mitochondrial genome do not display any unusual characteristics (Table 6).

\section{Gene rearrangement and nucleotide composition}

The mitochondrial genome of symphytan species appears to be more conserved than that of Apocrita (Song et al., 2016; Wei et al., 2014). However, compared with the putative ancestral 
523 mitochondrial genome of insects, we detected several rearrangement events in three tRNA gene 524 clusters in L. sinicus (Figure 5), The first rearrangement event is found in the clusters of trnI$525 \operatorname{trn} Q$-trnM, where $\operatorname{trn} M$ and $\operatorname{trn} Q$ was founding swapped positions, in addition, $\operatorname{trn} M$-trn $Q$ was

526

527

528

529

530

531

532

533

534

535

536

537

538

539

540

541

542

543

544

545

546

547

548

549

550

551

552

553

554

555

556

557

558

559

560

561

562

563

564

565 translocated from the trnI-trnQ-trnM cluster to a downstream position of $r r n S$; which have not been reported for any symphytan mitogenome to date. The second event is corresponding to the remote inversion of $\operatorname{trn} Y$ and the translocation of $\operatorname{trn} C$ from a location between $\operatorname{trn} W$ and $C O X I$ to upstream of $t r n I$, which has great similarity to the gene order and rearrangement events observed in $T$. anthracinum. The arrangement of cluster of $\operatorname{trn} W$-trnC-trnY appears to be mostly conserved in almost all known symphytan mitogenomes, except for representative cimbicid species. The last event is only found in the TP cluster of L. sinicus, and here trnT is inverted. The gene order from $\mathrm{COI}$ to $\mathrm{rrnS}$ is conserved in all sequenced species of Cimbicidae.

Similar to previously reported symphytan mitochondrial genomes (Ma et al., 2019; Doğan and Korkmaz, 2017; Song et al., 2016), the nucleotide compositions of L. sinicus $(43.5 \%$ A, 37.7\% $\mathrm{T}, 7.7 \% \mathrm{G}$ and $11.1 \% \mathrm{C}$ ) were biased towards $\mathrm{A}$ and $\mathrm{T}$, with an average $81.2 \% \mathrm{~A}+\mathrm{T}$ content; a stronger AT bias was found in the $\mathrm{N}$ strand (81.4\% A+T content) than in the J- strand (78.7\%) (Table 5).

Further analysis of the PCGs indicated that the third codon position demonstrates the highest $\mathrm{A}+$ T content (93.5\%), in agreement with symphytan mitochondrial genomes (Ma et al., 2019;

Doğan and Korkmaz, 2017; Song et al., 2016). The gene with the highest A + T content was ATP8 with $88.3 \%$ (Table 5). Here we observed that the AT-skew was slightly positive (0.0714), and the GC-skew was negative $(-0.1809)$ when considering the whole genome (Table 5). This indicates that the occurrence of $\mathrm{A}$ is higher than that of $\mathrm{T}$, and the occurrence of $\mathrm{C}$ is higher than that of $\mathrm{G}$, which is a general phenomenon observed in all reported symphytan mitochondrial genomes, except for those of Tremex columba and Xiphydria sp. (Ma et al., 2019; Doğan and Korkmaz, 2017; Song et al., 2016; Wei et al., 2015; Castro and Dowton, 2005; Dowton et al., 2009). However, a deviation was found in the PCGs of L. sinicus, in terms of AT-skew $(-0.1389)$ and GC-skew (0.0348), which also occurred in both C. lateralis and T. anthracinum. This deviation can exert influences on the selection forces acting on the PCG codon positions, in accordance with study by Korkmaz et al. (2015).

\section{Transfer RNA genes}

In the mitochondrial genome of L. sinicus 15 tRNAs were encoded by the J- strand, while the remaining tRNAs were encoded by the opposite N-strand. All tRNAs folded into a common clover-leaf structure, except trns 1-AGN, where the dihydrouridine (DHU) arm was missing (Figure 6). The size of the tRNAs ranged from $64 \mathrm{bp}(\operatorname{trn} G)$ to $71 \mathrm{bp}(\operatorname{trn} C, \operatorname{trn} K)$, and this usually depends on the length of the variable loop, TYC loop and D-loops (Clary and

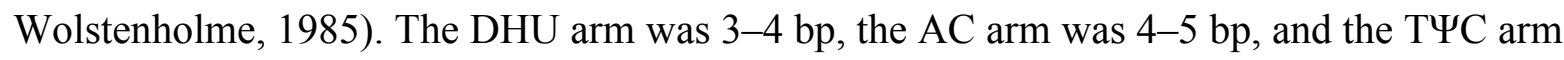
varied from 4-5 bp, while the amino acid acceptor (AA) stem and anticodon (AC) loops were conserved at $7 \mathrm{bp}$ in all of the tRNA genes.

In the mitochondrial tRNA secondary structures, mismatches mainly occur in the DHU arm, AA

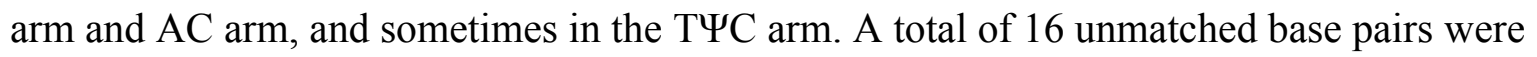
scattered among the following tRNA genes, including $12 \mathrm{G}-\mathrm{U}$ mismatched pairs occurring in $\operatorname{trn} A, \operatorname{trn} D, \operatorname{trn} Q, \operatorname{trn} G, \operatorname{trn} H, \operatorname{trn} L 1, \operatorname{trn} P, \operatorname{trn} F$, and $\operatorname{trn} Y$, and four U-U mismatches occurring in

Peer] reviewing PDF | (2019:01:34672:4:0:NEW 3 Sep 2019) 
$566 \operatorname{trnR}$, $\operatorname{trn} T$ and $\operatorname{trn} L 1$. The number of mismatches were $24(12 \mathrm{G}-\mathrm{U}$ pairs, five $\mathrm{U}-\mathrm{U}$ pairs, three 567 A-A pairs, two A-C pairs, one A-G pair and one $\mathrm{C}-\mathrm{U}$ pair) in C. lateralis (Figure 7), and 18 (15 568 G-U pairs, two U-U pairs and $1 \mathrm{~A}-\mathrm{C}$ pair) in T. anthracinum (Figure 6), which is typical for 569 Hymenoptera (Ma et al., 2019; Castro and Dowton, 2005; Dowton et al., 2009b). The

570 phenomenon of aberrant mismatches, loops, or extremely short arms for tRNAs has been shown 571 to be common in metazoan mitochondrial genomes (Wolstenholme, 1992).

572 In addition, there were some tRNA structural differences between $L$. sinicus and $T$. anthracinum

573 (Figure 6). The identified anticodons were almost identical to those of the cimbicid species, with 574 the exception of the anticodon of $\operatorname{trnSl}(A G n)$, which is UCU in L. sinicus and T. anthracinum, 575 as well as this is true of all previously reported of Symphyta (Ma et al., 2019; Doğan and

576

577

578

579

580

581

582

583

584

585

586

587

588

589

590

591

592

593

594

595

596

597

598

599

600

601

602

603

604

605

\section{Ribosomal RNA genes}

The $r r n L$ gene of $L$. sinicus was 1,341 bp in length with an $84.2 \% \mathrm{~A}+\mathrm{T}$ content, while $r r n S$ was $791 \mathrm{bp}$ in length with an $84.1 \% \mathrm{~A}+\mathrm{T}$ content (Table 5). This was in a comparable range to homologous genes in T. anthracinum (1,351 bp; $800 \mathrm{bp}$ ) and C. lateralis (1,359 bp; $493 \mathrm{bp} r \mathrm{rnS}$ partial gene), and also identical to all reported hymenopteran species (Gillespie, 2006; Wei et al., 2010, Doğan and Korkmaz, 2017; Song et al., 2016; Korkmaz et al., 2015). Both genes were encoded on the N-strand (Table 4).

Similar to the known symphytan mitochondrial genomes, the $r r n L$ gene is positioned between trnL1 and trnV in three species of Cimbicidae (Figure 5). The predicted structure of $r r n L$ in $L$. sinicus is consistent with the observed pattern in C. lateralis and T. anthracinum, whereby 45 helices belonging to five domains were identified in those species (Figures 8,9 ). Domain III is absent as in other arthropods (Korkmaz et al., 2015), and domain II is variable in base composition, forming a long stem with a big loop structure in the area II terminal. Domains IV and $\mathrm{V}$ are more conserved within the Tenthredinidae than domains I, II and VI. Eight helices (H563, H579, H777, H822, H2023, H2043, H2455 and H2547) of $r r n L$ are highly conserved. The H183, H991, H1057, H1 196 and H2077 helices display helical length and loop size/structure variability within three cimbicid $r r n L$ genes (Figures 8,9 ).

The $r r n S$ secondary structure of $L$. sinicus is between $\operatorname{trn} V$ and an AT-rich region, and contains four domains and 26 helices. Compared with $T$. anthracinum, it is significantly different in terms of base composition in domain II (Figure 10). Specifically, H47 is variable among the different hymenopteran species, having a large loop. The loop size is variable and determined by overall $r r n S$ length, except for in the cephid species (Gillespie, 2006; Wei et al., 2010, Doğan and Korkmaz, 2017; Song et al., 2016; Korkmaz et al., 2015). The structures of domains I and II of C. lateralis are missing, so they cannot be compared with those of $L$. sinicus, but the structures are similar in domains III and IV (Figure 11). In $r r n S$, domain III and domain VI were more conserved within Tenthredinidae than domains I and II (Figures 10, 11).

\section{Phylogenetic relationships}


606 Phylogenetic relationships within the "Symphyta" were reconstructed using both BI and ML 607 analyses. The topologies of the two phylogenetic trees were almost identical, thus we combined 608 the two phylogenetic trees (Figure 12). The clade consisting of (Tenthredinidae + Cimbicidae) + 609 (Argidae + Pergidae), was very stable with the highest nodal supports. The recovered trees 610 supported a relationship consisting of Xyelidae + (Tenthredinoidea + (Pamphiliidae + 611 ((Megalodontesidae + Xiphydriidae $)+($ Cephidae $+($ Orussidae $+($ Siricidae + Apocrita $)))))$ in 612 Hymenoptera. It seems unusual that Siricidae is the sister group to Apocrita, although, the sister 613 relation of Tremex columba (MH422968) and Tremex columba (AY206795) according to the 614 phylogenetic inference based on IV and V areas of rrnL (YY Zhang, 2019, unpublished data), 615 suggests the former is valid. It showed that more mitochondrial genomes should be involved to 616 evaluate the correctness of these unusual sister groups.

617 To investigate the phylogenetic relationships of Labriocimbex within Cimbicidae, we analyzed 61843 cimbicid and two outgroups sequences, an approximately 850-bp piece of the COI gene were 619 obtained in this study, combined with the other species sequences from GenBank aligned by 620 MAFFT. The phylogenetic trees were reconstructed using both BI and ML analyses (Figure 13). 621 We found that the generic relationships of Cimbicidae revealed by the phylogenetic analyses 622 based on COI genes agree quite closely with the systematic arrangement of the genera based on 623 the morphological characters.

624 The subfamily classification scheme suggested by Abe and Smith (1991) is confirmed by the 625 results of the present analyses. The monotypic Corynidinae are always retrieved with strong 626 support, and Abiinae + Cimbicinae is best-supported internal node in the present analyses of 627 Cimbicidae, which was also supported by Vilhelmsen (2019).

628 The clade consisting of $(((($ Labriocimbex + Praia $)+$ T. anthracinum $)+$ Trichiosoma $)+$ 629 Leptocimbex) + Cimbex, was highly supported in both trees (posterior probability $>0.9511$ and 630 bootstrap support $>87$ ). Labriocimbex is always retrieved as monophyletic (two samples were 631 collected in Hunan, one was collected in Zhejiang), and it is the sister group of Praia. Praia + 632 Labriocimbex is the sister group of T. anthracinum. Malaise (1939) placed T. anthracinum and 633 other two species, T. hymalayensis and T. sikkimensis, in the subgenus Asitrichiosoma within

634 Trichiosoma. According to our analyses (Figure 13), T. anthracinum renders the genus

635 Trichiosoma paraphyletic, and it is necessary to reestablish the genus Asitrichiosoma.

636 Additionally, we demonstrated that COI gene sequences can be used to solve phylogenetic 637 relationships between genera of Cimbicidae. However, to reconstruct the generic phylogeny of 638 Cimbicidae the further studies of the mitochondrial genomes and external morphology of more 639 taxa of the family are needed.

640

\section{CONCLUSIONS}

642 Labriocimbex gen. nov. was regarded similar to the genera Trichiosoma Leach and Praia Andre. 643 Most of the characteristics of the new genus suggest placing it in the tribe Trichiosomini. The 644 most important characteristics include: the labrum large with the basal breadth about half the 645 breadth of clypeus, the jugum region in hind wing without crossvein, the clypeus very short and 
646 much broader than lower distance between eyes and not merging with supraclypeal area.

647 Following characters help to distinguish this new genus and new species: the clypeus and labrum

648 black; the clypeus broadly and shallowly emarginated; the labrum triangular and tapering toward

649 apex, basal breadth about half the breadth of clypeus; the apical anal cell about 2 times as long as

650 basal anal cell; the hind femora close to each other and without ventral denticle; the very large

651 tarsal pulvilli; malar space 2.3 times the diameter of lateral ocellus; the inner margins of eyes

652 parallel; head distinctly dilated behind eyes; the inner spur of hind tibia as long as apical breadth

653 of tibia, apex blunt and membranous; the long and dense hairs covering head, thorax, base of

654 abdomen and legs.

655 The complete mitochondrial genome of L. sinicus was obtained and was found to have a length

656 of 15,405 bp and a typical set of 37 genes. The secondary structures of the 22 tRNAs and two

657 rRNAs resemble those of Symphyta. In comparison with the structures of T. anthracinum and $C$.

658 lateralis, some helices were highly variable in $r r n L$ and $r r n S$.

659 The same cladograms were obtained using two different analytical methods, and our findings

660 partly disagreed with traditional morphological classification. The tree topology confirmed that

661 Cimbicidae is a member of the superfamily Tenthredinoidea and Labriocimbex gen. nov. is a

662 member of Cimbicidae.

663 Within Cimbicidae, we have made several interesting discoveries, including a proposal to place

664 the Praia into tribe Trichiosomini, and to promote the subgenus Asitrichiosoma to be a valid

665 genus. Based on COI data, the phylogenetic position of Labriocimbex showed that it is the sister

666 group of Praia, Labriocimbex + Praia is the sister group of Asitrichiosoma anthracinum, and

667 Labriocimbex + Praia + Asitrichiosoma is the sister group of Trichiosoma. The positions of

668 Labriocimbex and its close relatives remain to be decided in future studies. Here we suggest that

669 Labriocimbex belongs to the tribe Trichiosomini of Cimbicinae based on adult morphology and

670 molecular data.

671

\section{ACKNOWLEDGMENTS}

673 Thank Dr. Zejian Li of the Lishui Academy of Forestry, Zhejiang province, China, for collecting

674 specimens from Mt. Tianmu. The members of Lab of Insect Systematics and Evolutionary

675 Biology (LISEB) from Central South University of Forestry and Technology are thanked for

676 their contributions in laboratory work. We thank all the reviewers for their comments.

677

\section{REFERENCES}

679 Abe M, Smith DR. 1991. The genus-group names of Symphyta (Hymenoptera) and their type

$680 \quad$ species. Esakia 31:1-115.

681 Beard CB, Hamm DM, Collins FH. 1993. The mitochondrial genome of the mosquito Anopheles

682 gambiae: DNA sequence, genome organization, and comparisons with mitochondrial

683 sequences of other insects. Insect Molecular Biology 2(2):103-124.

684 Benson RB. 1938. On the classification of Sawflies (Hymenoptera, Symphyta). Transactions of

685 the Entomological Society of London 87:353-384. 
686 Bernt M, Donath A, Jühling F, Externbrink F, Florentz C, Fritzsch G, Pütz J, Middendorf M,

687

688

689

690

691

692

693

694

695

696

697

698

699

700

701

702

703

704

705

706

707

708

709

710

711

712

713

714

715

716

717

718

719

720

721

722

723

724

725

Stadler PF. 2013. MITOS: improved de novo metazoan mitochondrial genome annotation. Molecular Phylogenetics and Evolution 69:313-319.

Blank SM, Groll EK. Liston A, Prous M, Taeger A. 2012. ECatSym - Electronic World Catalog of Symphyta (Insecta, Hymenoptera). Program Version 4.0 Beta, Data Version 39. Digital Entomological Information, Müncheberg. URL http://sdei.senckenberg.de/ecatsym.

Castro LR, Dowton M. 2005. The position of the Hymenoptera within the Holometabola as inferred from the mitochondrial genome of Perga condei (Hymenoptera: Symphyta: Pergidae). Molecular Phylogenetics and Evolution 34(3):469-479.

Deng TJ. 2000. A systematic study of Cimbicidae from China (Hymenoptera: Symphyta) (In Chinese, abstract in English). Central south forest university. Thesis for Master degree. Zhuzhou, Hunan province, China.

(http://www.wanfangdata.com.cn/details/detail.do?_type=degree\&id=Y366423)

Dierckxsens N, Mardulyn P, Smits G. 2017. NOVOPlasty: de novo assembly of organelle genomes from whole genome data. Nucleic Acids Research 45:e18.

De Rijk P, Wuyts J, De Wachter R. 2003. RnaViz 2: an improved representation of RNA secondary structure. Bioinformatics 19:299-300.

Darty K, Denise A, Ponty Y. 2009. VARNA: Interactive drawing and editing of the RNA secondary structure. Bioinformatics 25:1974-1975.

Doğan Ö, Korkmaz EM. 2017. Nearly complete mitogenome of hairy sawfly, Corynis lateralis (Brullé, 1832) (Hymenoptera: Cimbicidae): rearrangements in the IQM and ARNS1EF gene clusters. Genetica 145:341-350.

Dowton M, Cameron SL, Austin AD, Whiting MF. 2009. Phylogenetic approaches for the analysis of mitochondrial genome sequence data in the Hymenoptera-a lineage with both rapidly and slowly evolving mitochondrial genomes. Molecular Phylogenetics \& Evolution 52:512-519.

Du SY, Niu GY, Nyman T, Wei MC. 2018. Characterization of the mitochondrial genome of Arge bella Wei \& Du sp. nov. (Hymenoptera: Argidae). PeerJ 6:e6131.

Foster PG, Jermiin LS, Hickey DA. 1997. Nucleotide Composition Bias Affects Amino Acid Content in Proteins Coded by Animal Mitochondria. Journal of Molecular Evolution 44:282288.

Gillespie JJ, Johnston JS, Cannone JJ, Gutell RR. 2006. Characteristics of the nuclear (18S, 5.8S, 28S and 5S) and mitochondrial (12S and 16S) rRNA genes of Apis mellifera (Insecta: Hymenoptera): structure, organization, and retrotransposable elements. Insect molecular biology 15:657-686.

Gauld I, Bolton B.1988. The Hymenoptera. British Museum (Natural History). Oxford: Oxford University Press.

Hahn C, Bachmann L, Chevreux B. 2013. Reconstructing mitochondrial genomes directly from genomic next-generation sequencing read-a baiting and iterative mapping approach. Nucleic Acids Research 41:129-129.

Peer] reviewing PDF | (2019:01:34672:4:0:NEW 3 Sep 2019) 
726

727

728

729

730

731

732

733

734

735

736

737

738

739

740

741

742

743

744

745

746

747

748

749

750

751

752

753

754

755

756

757

758

759

760

761

762

763

Hebert PDN, Ratnasingham S, Zakharov EV, Telfer AC, Levesque-Beaudin V, Milton MA, Pedersen S, Jannetta P, deWaard JR. 2016. Counting animal species with DNA barcodes: Canadian insects. Phil. Trans. R. Soc. B 371:20150333.

Heraty J, Ronquist F, Carpenter JM. Hawks D, Schulmeister S, Dowling AP, Murray D, Munro J, Wheeler WC, Schiff N, Sharkey M. 2011. Evolution of the hymenopteran megaradiation. Molecular Phylogenetics and Evolution 60:73-88.

Hyde J, Cooper SJB, Munguia P, Humphreys WF, Austin AD. 2018. The first complete mitochondrial genomes of subterranean dytiscid diving beetles (Limbodessus and Paroster) from calcrete aquifers of Western Australia. Australian Journal of Zoology 65:283-291.

Isaka Y, Sato, T. 2015. Was species diversification in Tenthredinoidea (Hymenoptera:

Symphyta) related to the origin and diversification of angiosperms? The Canadian Entomologist 147:443-458.

Korkmaz EM, Doğan Ö, Durel BS, Temel Altun B, Budak M, Başıüyük HH. 2018. Mitogenome organization and evolutionary history of the subfamily Cephinae (Hymenoptera: Cephidae). Systematic Entomology 43(3):606-618.

Korkmaz EM, Aydemir HB, Temel B, Budak M, Başıüyük HH. 2017. Mitogenome evolution in Cephini (Hymenoptera: Cephidae): Evidence for parallel adaptive evolution. Biochemical Systematics and Ecology 71:137-146.

Korkmaz EM, Budak M, Ördek MN, Başibüyük HH. 2016. The complete mitogenomes of Calameuta filiformis (Eversmann, 1847) and Calameuta idolon (Rossi, 1794) (Hymenoptera:

Cephidae): The remarkable features of the elongated $\mathrm{A}+\mathrm{T}$ rich region in Cephini. Gene 576:404-411.

Korkmaz EM, Doğan Ö, Budak M, Başibüyük HH. 2015. Two nearly complete mitogenomes of wheat stem borers, Cephus pygmeus (L.) and Cephus sareptanus Dovnar-Zapolskij (Hymenoptera: Cephidae): An unusual elongation of $r r n S$ gene. Gene 558:254-264.

Kumar S, Stecher G, Tamura K. 2016. MEGA7: Molecular Evolutionary Genetics Analysis version 7.0 for bigger datasets. Molecular Biology and Evolution 33:1870-1874.

Klopfstein S, Vilhelmsen L, Heraty JM, Sharkey M, Ronquist F. 2013. The Hymenopteran Tree of Life: Evidence from Protein-Coding Genes and Objectively Aligned Ribosomal Data). PLoS ONE 8(8):e69344.

Katoh K, Standley DM. 2013. MAFFT multiple sequence alignment software version 7: improvements in performance and usability. Molecular Biology and Evolution 30:772-780.

Lanfear R, Calcott B, Ho SYW, Guindon S. 2012. Partition Finder: Combined selection of partitioning schemes and substitution models for phylogenetic analyses. Molecular Biology and Evolution 29:1695-1701.

Leppänen SA, Altenhofer E, Liston AD, Nyman T. 2012. Phylogenetics and evolution of hostplant use in leaf-mining sawflies (Hymenoptera: Tenthredinidae: Heterarthrinae). Molecular Phylogenetics and Evolution 64:331-341. 
764

765

766

767

768

769

770

771

772

773

774

775

776

777

778

779

780

781

782

783

784

785

786

787

788

789

790

791

792

793

794

795

796

797

798

799

800

801

802

Li YG, Wu XY. 2010. The Investigation and Taxonomical Research of the Sawflies Species from Gansu Province III. A list of the genera and species (Hymenoptera: Cimbicidae). Journal of Gansu Forestry Science and Technology 35(1):12-14.

Liston AD, Savina H, Nagy ZT, Sonet G, Boeve JL. 2014. Taxonomy, phylogeny and host plants of some Abia sawflies (Hymenoptera, Cimbicidae). Zootaxa 3821(1):125-132.

Luo R, Liu B, Xie Y, Li Z, Huang W, Yuan J, He G, Chen Y, Qi P, Liu Y. 2012. SOAPdenovo2: an empirically improved memory-efficient short-read de novo assembler. Gigascience 1:1-18.

Malm T, Nyman T. 2015. Phylogeny of the symphytan grade of Hymenoptera: new pieces into the old jigsaw (fly) puzzle. Cladistics 31:1-17.

Malaise R. 1939. The Genus Leptocimbex Sem., and some other Cimbicidae. Entomologisk Tidskrift 60:1-28.

Malaise R.1934. Schwedisch-chinesische wissenschaftliche Expedition nach den nordwestlichen Provinzen Chinas unter Leitung von Dr. Sven Hedin und Prof. Sü Ping-Chang. Insekten gesammelt vom schwedischen Arzt der Expedition Dr. David Hummel 1927-1930.

Misof B, Fleck G. 2003. Comparative analysis of mt LSU rRNA secondary structures of Odonates: Structural variability and phylogenetic signal. Insect Molecular Biology 12(6):535547.

Ma Y, Zheng BY, Zhu JC, Achterberg CV, Tang P, Chen XX. 2019. The first two mitochondrial genomes of wood wasps (Hymenoptera: Symphyta): Novel gene rearrangements and higherlevel phylogeny of the basal hymenopterans. International Journal of Biological Macromolecules 123:1189-1196.

Nawrocki EP. 2009. Structural RNA homology search and alignment using covariance models. Washington: University in St. Louis.

Niu GY, Korkmaz EM, Doğan Ö, Zhang YY, Aydemir MN, Budak M, Du SY, Başıbüyük HH, Wei MC. 2019. The first mitogenomes of the superfamily Pamphilioidea (Hymenoptera: Symphyta): Mitogenome architecture and phylogenetic inference. International Journal of Biological Macromolecules 124:185-199.

Niu GY, Zhang YY, Li ZY, Wei MC. 2019. Characterization of the mitochondrial genome of Analcellicampa xanthosoma gen. et sp. nov. (Hymenoptera: Tenthredinidae). PeerJ 7:e6866. Nyman T, Zinovjev AG, Vikberg V, Farrell BD. 2006. Molecular phylogeny of the sawfly subfamily Nematinae (Hymenoptera: Tenthredinidae). Systematic Entomology 31(4):569-583. Perna NT, Kocher TD. 1995. Patterns of nucleotide composition at fourfold degenerate sites of animal mitochondrial genomes. Journal of Molecular Evolution 41:353-358.

Peng Y, Chen B, LI TJ. 2017. Sequencing and analysis of the complete mitochondrial genome of Parapolybia crocea (Hymenoptera:Vespidae). Acta Entomologica Sinicus 60(4):464-474.

Peters RS, Krogmann L, Mayer C, Donath A, Gunkel S, Meusemann K, Kozlov A, Podsiadlowski L, Petersen M, Lanfear R, Diez PA, Heraty J, Kjer KM, Klopfstein S, Meier R, Polidori C. Schmitt T. Liu S, Zhou X, Wappler T, Rust J, Misof B, Niehuis O. 2017. Evolutionary history of the Hymenoptera, Current Biology 27:1-6.

Peer] reviewing PDF | (2019:01:34672:4:0:NEW 3 Sep 2019) 
803 Ronquist F, Teslenko M, Van Der Mark P, Ayres DL, Darling A, Höhna S, Larget B, Liu L, 804 Suchard M a, Huelsenbeck JP. 2012. Mrbayes 3.2: Efficient bayesian phylogenetic inference 805 and model choice across a large model space. Systematic Biology 61:539-542.

806 Ross HH. 1945. Sawfly genitalia: terminology and study techniques. Entomological News 807 61(10):261-268.

808 Ross HH. 1937. A Generic Classification of the Nearctic Sawflies (Hymenoptera: Symphyta). 809 Illinois biological monographs Urbana 15(2):1-173.

810 Sharkey MJ, Carpenter JM, Vilhelmsen L, Heraty J, Dowling APG, Schulmeister S, Murray D, 811 Andrew R, Ronquist F, Krogmann L, Wheeler WC. 2012. Phylogenetic relationships among 812 superfamilies of Hymenoptera. Cladistics 28:80-112.

813 Schmidt S, Taeger A, Morinière J, Liston A, Blank SM, Kramp K, Kraus M, Schmidt O, Heibo

814 E, Prous M, Nyman T, Malm T, Stahlhut J. 2017. Identification of sawflies and horntails

815 (Hymenoptera, 'Symphyta') through DNA barcodes: successes and caveats. Molecular

816 Ecology Resources 17:670-685.

817 Schmidt S, Walter GH. 2014. Young clades in an old family: major evolutionary transitions and

818 diversification of the eucalypt feeding pergid sawflies in Australia (Insecta, Hymenoptera,

819 Pergidae). Molecular Phylogenetics and Evolution 74:111-121.

820 Schulmeister S.2003. Simultaneous analysis of basal Hymenoptera (Insecta): introducing robust-

821 choice sensitivity analysis. Biological Journal of the Linnean Society. Linnean Society of

822 London79:245-275.

823 Schulmeister S, Wheeler WC, Carpenter JM. 2002. Simultaneous analysis of the basal lineages

824 of Hymenoptera (Insecta) using sensitivity analysis. Cladistics 18:455-484.

825 Shinohara A, Kiyoshi T, Kameda Y. 2016. New Distribution Records of Two Species of Arge

826 and Spinarge (Hymenoptera, Argidae) from Kyushu, Japan. Bulletin of the National Museum

827 of Nature and Science. Series A 42:81-85.

828 Siebert S, Backofen R. 2005. MARNA: multiple alignment and consensus structure prediction of

829 RNAs based on sequence structure comparisons. Bioinformatics 21:3352-3359.

830 Song SN, Tang P, Wei SJ, Chen XX. 2016. Comparative and phylogenetic analysis of the

831 mitochondrial genomes in basal hymenopterans. Scientific Reports 6(1):20972-20972.

832 Song SN, Wang ZH, Li Y, Wei SJ, Chen XX. 2015. The mitochondrial genome of Tenthredo

833 tienmushana (Takeuchi) and a related phylogenetic analysis of the sawflies (Insecta:

834 Hymenoptera). Mitochondrial DNA 27(4):1-2.

835 Taeger A, Blank SM, Liston AD. 2010. World catalog of Symphyta (Hymenoptera). Zootaxa

$836 \quad 2580: 1-1064$.

837 Takeuchi K. 1952. A generic Classification of the Japanese Tenthredinidae (Hymenoptera:

838 Symphyta). Kyoto.

839 Tang P, Zhu JC, Zheng BY, Wei SJ, Sharkey MJ, Chen XX, Vogler AP. 2019. Mitochondrial

840 phylogenomics of the Hymenoptera. Molecular Phylogenetics and Evolution 131:8-18. 
841 Vaidya G, Lohman DJ, Meier R. 2011. Sequence Matrix: Concatenation software for the fast 842 assembly of multi-gene datasets with character set and codon information. Cladistics 27:171843180.

844 Viitasaari M. 2002. Sawflies (Hymenoptera, Symphyta) I. A review of the suborder, the Western

845 Palaearctic taxa of Xyeloidea and Pamphilioidea. Helsinki: Tremex Press Ltd.

846 Vilhelmsen L. 2019. Giant sawflies and their kin: morphological phylogeny of Cimbicidae

847 (Hymenoptera). Systematic Entomology 44:103-127.

848 Vilhelmsen L.2015. Morphological phylogenetics of the Tenthredinidae (Insecta: Hymenoptera).

849 Invertebrate Systematics 29:164-190.

850 Vilhelmsen L. 2001. Phylogeny and classification of the extant basal lineages of the

851 Hymenoptera (Insecta), Zoological Journal of the Linnean Society 131:393-442.

852 Wei MC. Nie HY.1997. Preliminary phylogeny of Symphyta (Hymenoptera). Journal of Central 853 South Forestry University 17(1):36-41.

854 Wei SJ, Wu QL, Liu W. 2015. Sequencing and characterization of the Monocellicampa pruni 855 (Hymenoptera: Tenthredinidae) mitochondrial genome. Mitochondrial DNA 26:157-158.

856 Wei SJ, Niu FF, and Du BZ. 2014. Rearrangement of trnQ-trnM in the mitochondrial genome of 857 Allantus luctifer (Smith) (Hymenoptera: Tenthredinidae). Mitochondrial DNA Part A 858 27(2):856-858.

859 Wei SJ, Shi M, Chen XX, Sharkey MJ, Achterberg CV, Ye GY, He JH. 2010. New views on 860 strand asymmetry in insect mitochondrial genomes. PlosOne 5(9):1-10.

861 Wolstenholme DR. 1992. Animal mitochondrial DNA: structure and evolution. International

862 Review of Cytology 141:173-216

863 Wu QL, Li Q, Gu Y, Shi BC, van Achterberg C, Wei SJ, Chen XX. 2014. The complete 864 mitochondrial genome of Taeniogonalos taihorina (Bischoff) (Hymenoptera: Trigonalyidae) reveals a novel gene rearrangement pattern in the Hymenoptera. Gene 543:76-84.

Yan YC, Niu GY, Lan BC, Wei MC. 2018. Review of Leptocimbex formosanus group (Hymenoptera: Cimbicidae) with two new Chinese species, Entomological Research 48:372383.

Yan YC, Wei MC. 2016. A new species and a new record of Leptocimbex Semenov (Hymenoptera: Cimbicidae) from China. Entomotaxonomia 38:227-234.

Yan YC, Xiao W, Wei MC. 2014. Two new species of Leptocimbex Semenov (Hymenoptera: Cimbicidae) from China. Entomotaxonomia 36:311-320.

Yan YC, Wei MC. 2013. A new species of the genus Leptocimbex Semenov-Tian-Shanskij (Hymenoptera, Cimbicidae) from Hunan, China. Acta Zootaxonomica Sinicus 38:130-133.

Yan YC, Wei MC. 2010. The first record of Orientabia malaise from China with description of a new species (Hymenoptera, Cimbicidae). Acta Zootaxonomica Sinicus 35(3):627-630.

Zhao Y, Zhang H, Zhang Y. 2017. Complete mitochondrial genome of Neochauliodes parasparsus (Megaloptera: Corydalidae) with phylogenetic consideration. Biochemical

880

881

Notes 
882 Table 1. Summary information of symphytan mitochondrial genomes used in phylogenetic 883 analyses.

884 Table 2. Specimens information of Cimbicidae and accession numbers of the GenBank sequences 885 used in phylogenetic analyses.

886 Table 3. The partitions of the mitochondrial genome sequences identified by PartitionFinder.

887 Table 4. Mitochondrial genome characteristics of L. sinicus.

888 Table 5. Nucleotide composition of $L$. sinicus mitochondrial genome.

889 Table 6. Codon usage of PCGs in mitochondrial genome of L. sinicus. No., frequency of each 890 codon; RSCU, relative synonymous condon usage.

891

892 Figure 1. Labriocimbex sinicus Yan \& Wei sp. nov.

893 A. Adult female (holotype), dorsal view; B. Adult male (paratype), dorsal view. Scale bar $=2$ $894 \mathrm{~mm}$.

895

896 Figure 2. Labriocimbex sinicus Yan \& Wei, gen. et sp. nov.

897 A. Head of female, front view; B. Head of female, lateral view; C. Mesopleuron of female, 898 lateral view; D. Head of female, dorsal view; E. Metanotum and base of abdomen; F. Abdomen, 899 lateral view; G. Palpus; H. Antenna of female.

900

901 Figure 3. Labriocimbex sinicus Yan \& Wei, gen. et sp. nov.

902 A. Left mandible; B. Right mandible; C. Femur of hind leg; D. Ovipositor sheath of female, 903 lateral view; E. Genital plate of male, ventral view; F. Ovipositor sheath of female, dorsal view; 904 G. Middle serrulae, Scale bar = 50 um; H. Penis valve; I. Gonoforcep. J. Spur of hind tibia; K. 905 Claw; L. Apex of abdomen, ventral view; M. Lance; N. Lancet (H, I, M and N, Scale bar $=200$ $906 \mathrm{um})$.

907

908 Figure 4. Labriocimbex zaraeoides (Malaise, 1939) comb. nov.

909 A. Adult female (holotype), Scale bar $=2 \mathrm{~mm}$; B. Mesopleuron of female, lateral view; C. Head 910 of female, front view; D. Abdomen, lateral view; E. Head of female, dorsal view; F. Head of 911 female, lateral view; G. Metanotum and basal of abdominal terga, dorsal view; H. Labels.

912

913 Figure 5. Mitochondrial genome organization of three cimbicid species referenced with the 914 ancestral insect mitochondrial genomes. Genes transcribed from the J- and N- strands are shown 915 with green and orange color, respectively. Overlapping and intergenic regions are marked in 916 yellow and blue circles. tRNA genes are denoted by a one-letter symbol according to the IPUC917 IUB single-letter amino acid codes A+ T-rich region is marked in blue and tRNA genes are 918 labelled by the single-letter amino acid code.

919 A. Ancestral type of insect mitochondrial genomes; B. Corynis lateralis mitochondrial genome; C. 920 Trichiosoma anthracinum mitochondrial genome; D. Labriocimbex sinicus mitochondrial genome. 
921 Figure 6. Predicted secondary structures for the 22 typical tRNA genes of L. sinicus and T.

922 anthracinum (adapted from Doğan and Korkmaz, 2017) mitogenomes. Base-pairing is indicated

923 as follows: Watson-Crick pairs by lines, wobble GU pairs by dots and other noncanonical pairs

924 by circles. Variable regions are presented in boxes with red (L. sinicus) and blue ( $T$.

925 anthracinum) color.

926 A. $\operatorname{trn} A ;$ B. $\operatorname{trnR}$; C. $\operatorname{trnN}$; D. $\operatorname{trn} D ;$ E. $\operatorname{trn} C ;$ F. $\operatorname{trn} Q ;$ G. $\operatorname{trn} E$; H. $\operatorname{trn} G$; I. $\operatorname{trnH}$; J. trnI; K. $\operatorname{trnL1}$;

927 L. $\operatorname{trnL2}$; M. $\operatorname{trnK}$; N. $\operatorname{trnM}$; O. trnF; P. $\operatorname{trnP}$; Q. trnS1; R. trnS2; S. trnT; T. trnW; U. trnY; V.

$928 \operatorname{trn} V$.

929

930 Figure 7. Predicted secondary structures for the 22 tRNA genes of C. lateralis (adapted from 931 Song et al., 2016). Dashes indicate Watson-Crick base pairing and dots indicate G-U base

932 pairing.

933 A. $\operatorname{trn} A ;$ B. $\operatorname{trnR}$; C. $\operatorname{trnN}$; D. $\operatorname{trn} D ;$ E. $\operatorname{trn} C ;$ F. $\operatorname{trn} Q ;$ G. $\operatorname{trn} E$; H. $\operatorname{trn} G$; I. $\operatorname{trnH}$; J. trnI; K. trnL1;

934 L. $t r n L 2 ;$ M. $t r n K ;$ N. trnM; O. trnF; P. $\operatorname{trnP}$; Q. trnS1; R. trnS2; S. trnT; T. trnW; U. trnY; V.

$935 \operatorname{trn} V$.

936

937 Figure 8. The predicted secondary structures of $r r n L$ of $L$. sinicus and T. anthracinum.

938 Tertiary interactions and base triples are connected by continuous lines. The numbering of helix

939 follows Gillespie et al. (2006). Roman numbers refer to domain names. Dashes indicate Watson-

940 Crick base pairing and dots indicate G-U base pairing. The helical variation among cimbicid

941 species are presented in boxes with red (L. sinicus) and blue (T. Anthracinum) color.

942

943 Figure 9. Corynis lateralis rrnL.

944 Predicted $r r n L$ secondary structure in C. lateralis. The numbering of helix follows Gillespie et al.

945 (2006). Roman numbers refer to domain names.

946

947 Figure 10. The predicted secondary structures of $r r n S$ of L. sinicus and T. anthracinum.

948 Tertiary interactions and base triples are connected by continuous lines. The numbering of helix

949 follows Gillespie et al. (2006). Roman numbers refer to domain names. Dashes indicate Watson-

950 Crick base pairing and dots indicate G-U base pairing. The helical variation among cimbicid

951 species are presented in boxes with red (L. sinicus) and blue (T. anthracinum) color.

952

953 Figure 11. Corynis lateralis rrnS.

954 Predicted $r r n S$ secondary structure in C. lateralis. The numbering of helix follows Gillespie et al.

955 (2006). Roman numbers refer to domain names.

956

957 Figure 12. Symphytan phylogenetic tree constructed with BI and ML approaches using a

958 mitochondrial genome dataset including 15 individual genes (13 PCGs and two rRNAs). Both

959 analyses produced the same tree topology. Support values lower than $100 \%$ in the ML analysis

960 and 1.0 in the BI analysis were shown.

961

Peer) reviewing PDF | (2019:01:34672:4:0:NEW 3 Sep 2019) 
962 Figure 13. Cimbicidae phylogenetic tree constructed with BI and ML approaches using the COI 963 gene data. Both analyses produced the same tree topology. Support values lower than $100 \%$ in 964 the ML analysis and 1.0 in the BI analysis were shown. 


\section{Table 1 (on next page)}

Summary information of symphytan mitochondrial genomes used in phylogenetic analyses. 


\begin{tabular}{|c|c|c|c|c|}
\hline & Species & Family & $\begin{array}{l}\text { Accesion } \\
\text { number }\end{array}$ & References \\
\hline \multirow[t]{36}{*}{ Ingroup } & Labriocimbex sinicus & Cimbicidae & MH136623 & this study \\
\hline & Corynis lateralis & Cimbicidae & KY063728 & Doğan and Korkmaz, 2017 \\
\hline & Trichiosoma anthracinum & Cimbicidae & KT921411 & Song et al., 2016 \\
\hline & Megalodontes cephalotes & Megalodontesidae & MH577058 & Niu et al., 2018 \\
\hline & Megalodontes spiraeae & Megalodontesidae & MH577059 & Niu et al., 2018 \\
\hline & Megalodontes quinquecinctus & Megalodontesidae & MG923502 & Tang et al., 2019 \\
\hline & Analcellicampa xanthosoma & Tenthredinidae & MH992752 & Niu et al., 2019 \\
\hline & Allantus luctifer & Tenthredinidae & KJ713152 & Wei et al., 2014 \\
\hline & Asiemphytus rufocephalus & Tenthredinidae & KR703582 & Song et al., 2016 \\
\hline & Monocellicampa pruni & Tenthredinidae & JX566509 & Wei et al., 2015 \\
\hline & Tenthredo tienmushana & Tenthredinidae & KR703581 & Song et al., 2015 \\
\hline & Birmella discoidalisa & Tenthredinidae & MF197548 & Unpublished \\
\hline & Xyela sp. & Xyelidae & MG923517 & Tang et al., 2019 \\
\hline & Xiphydria sp. & Xiphydriidae & MH422969 & Ma et al., 2018 \\
\hline & Tremex columba & Siricidae & MH422968 & Ma et al., 2018 \\
\hline & Pamphilius sp. & Pamphiliidae & MG923504 & Tang et al., 2019 \\
\hline & Chinolyda flagellicornis & Pamphiliidae & MH577057 & Niu et al., 2018 \\
\hline & Orussus occidentalis & Orussidae & FJ478174 & Dowton et al., 2009 \\
\hline & Arge similes & Argidae & MG923484 & Tang et al., 2019 \\
\hline & Arge bella & Argidae & MF287761 & Du et al., 2018 \\
\hline & Calameuta filiformis & Cephidae & KT260167 & Korkmaz et al., 2016 \\
\hline & Calameuta idolon & Cephidae & KT260168 & Korkmaz et al., 2016 \\
\hline & Cephus cinctus & Cephidae & FJ478173 & Dowton et al., 2009 \\
\hline & Cephus pygmeus & Cephidae & KM377623 & Korkmaz et al., 2015 \\
\hline & Cephus sareptanus & Cephidae & KM377624 & Korkmaz et al., 2015 \\
\hline & Characopygus scythicus & Cephidae & KX907848 & Korkmaz et al., 2018 \\
\hline & Hartigia linearis & Cephidae & KX907843 & Korkmaz et al., 2018 \\
\hline & Janus compressus & Cephidae & KX907844 & Korkmaz et al., 2018 \\
\hline & Pachycephus cruentatus & Cephidae & KX907845 & Korkmaz et al., 2018 \\
\hline & Pachycephus smyrnensis & Cephidae & KX907846 & Korkmaz et al., 2018 \\
\hline & Syrista parreyssi & Cephidae & KX907847 & Korkmaz et al., 2018 \\
\hline & Trachelus iudaicus & Cephidae & KX257357 & Korkmaz et al., 2017 \\
\hline & Trachelus tabidus & Cephidae & KX257358 & Korkmaz et al., 2017 \\
\hline & Perga condei & Pergidae & AY787816 & Castro and Dowton, 2005 \\
\hline & Taeniogonalos taihorina & Trigonalidae & NC027830 & Wu et al., 2014 \\
\hline & Parapolybia crocea & Vespidae & KY679828 & Peng et al., 2017 \\
\hline \multirow[t]{4}{*}{ Outgroup } & Paroster microsturtensis & Dytiscidae & MG912997 & Hyde et al., 2018 \\
\hline & Neopanorpa phlchra & Panorpidae & FJ169955 & Unpublished \\
\hline & Neochauliodes parasparsus & Corydalidae & KX821680 & Zhao et al., 2017 \\
\hline & Anopheles gambiae & Culicidae & L20934 & Beard et al., 1993 \\
\hline
\end{tabular}




\section{Table 2 (on next page)}

Specimens information of Cimbicidae and accession numbers of the GenBank sequences used in phylogenetic analyses. 


\begin{tabular}{|c|c|c|c|c|}
\hline Famil & subfamily & Genus*Species & $\begin{array}{l}\text { Accesion } \\
\text { number }\end{array}$ & References \\
\hline \multirow{33}{*}{$\begin{array}{l}\text { Cimbicidae } \\
\text { (ingroup) }\end{array}$} & Cimbicinae & Labriocimbex sinicus & MH136623 & this study \\
\hline & & Labriocimbex sinicus & MN076590 & this study \\
\hline & & Labriocimbex sinicus & MN076591 & this study \\
\hline & & Praia taczanowskii & KF936545 & Malm and Nyman, 2015 \\
\hline & & Praia taczanowskii & KC976900 & Schmidt et al., 2017 \\
\hline & & Cimbex americana & EF032218 & Schulmeister et al., 2002 \\
\hline & & Cimbex fagi & KC972801 & Schmidt et al., 2017 \\
\hline & & Cimbex luteus & KC973384 & Schmidt et al., 2017 \\
\hline & & Cimbex femoratus & KC976129 & Schmidt et al., 2017 \\
\hline & & Cimbex sp. & KF936524 & Malm and Nyman, 2015 \\
\hline & & Trichiosoma anthracinum & KT921411 & Song et al., 2016 \\
\hline & & Trichiosoma aenescens & JX090784 & Leppänen et al., 2012 \\
\hline & & Trichiosoma triangulum & KR895520 & Hebert et al., 2016 \\
\hline & & Trichiosoma sp. & KR878237 & Hebert et al., 2016 \\
\hline & & Trichiosoma lucorum & KF936518 & Malm and Nyman, 2015 \\
\hline & & Trichiosoma tibiale & KC976817 & Schmidt et al., 2017 \\
\hline & & Trichiosoma sorbi & KJ402312 & Liston et al., 2014 \\
\hline & & Leptocimbex sp. & KC976797 & Schmidt et al., 2017 \\
\hline & & Leptocimbex sp. & КC976130 & Schmidt et al., 2017 \\
\hline & & Leptocimbex sp. & KC975295 & Schmidt et al., 2017 \\
\hline & & Leptocimbex_potanini & MN076592 & this study \\
\hline & & Leptocimbex_linealis & MN076593 & this study \\
\hline & & Leptocimbex_afoveata & MN076594 & this study \\
\hline & & Leptocimbex_liisp. & MN076595 & this study \\
\hline & & Leptocimbex sp. & MN076596 & this study \\
\hline & & Leptocimbex_tuberculatus & MN076597 & this study \\
\hline & & Leptocimbex sp. & MN076598 & this study \\
\hline & & Leptocimbex grahami & MN076599 & this study \\
\hline & Abiinae & Abia niui & MN076604 & this study \\
\hline & & Abia berezowski & MN076605 & this study \\
\hline & & Abia candens & DQ302235 & Nyman et al., 2006 \\
\hline & Corynidinae & Corynis lateralis & KY063728 & Doğan \& Korkmaz, 2017 \\
\hline & & Corynis andrei & KF642787 & Schmidt et al., 2017 \\
\hline
\end{tabular}




\begin{tabular}{|c|c|c|c|c|}
\hline & & Corynis crassicornis & KF936612 & Malm and Nyman, 2015 \\
\hline & & Corynis mutabilis & KF642872 & Schmidt et al., 2017 \\
\hline & & Corynis krueperi & KF642852 & Schmidt et al., 2017 \\
\hline & & Corynis sanguinea & KF642775 & Schmidt et al., 2017 \\
\hline & & Corynis hispanica & KF642727 & Schmidt et al., 2017 \\
\hline & & Corynis enslini & KF642703 & Schmidt et al., 2017 \\
\hline & & Corynis caucasica & KF642648 & Schmidt et al., 2017 \\
\hline & & Corynis obscura & KC976955 & Schmidt et al., 2017 \\
\hline & & Corynis atricapilla & KC976741 & Schmidt et al., 2017 \\
\hline & & Corynis italica & KC975057 & Schmidt et al., 2017 \\
\hline Argidae & Arginae & Arge similis & MG923484 & Tang et al., 2019 \\
\hline (outgroup) & & Arge bella & MF287761 & Du et al., 2018 \\
\hline
\end{tabular}

2 


\section{Table 3 (on next page)}

The partitions of the mitochondrial genome sequences identified by PartitionFinder. 


\begin{tabular}{|c|c|c|c|}
\hline Partitions & $\begin{array}{c}\text { Best } \\
\text { Models }\end{array}$ & sites & genes \\
\hline $\mathrm{P} 1$ & $\mathrm{GTR}+\mathrm{I}+\mathrm{G}$ & 1568 & $r r n S$ \\
\hline $\mathrm{P} 2$ & $\mathrm{GTR}+\mathrm{I}+\mathrm{G}$ & 2032 & $r r n L$ \\
\hline P3 & $\mathrm{GTR}+\mathrm{I}+\mathrm{G}$ & 751 & ND3_1st, ATP6_1st, CYTB_1st \\
\hline $\mathrm{P} 4$ & $\mathrm{GTR}+\mathrm{I}+\mathrm{G}$ & 1784 & $N D 3 \_2 \mathrm{nd}, A T P 6 \_2 \mathrm{nd}, C O X 3 \_2 \mathrm{nd}, C Y T B \_2 \mathrm{nd}, C O X 2 \_2 \mathrm{nd}, C O X 1 \_2 \mathrm{nd}$ \\
\hline P5 & $\mathrm{GTR}+\mathrm{I}+\mathrm{G}$ & 1849 & ND3_3rd, COX2_3rd, ATP8_3rd, ATP6_3rd, COX1_3rd, COX3_3rd, CYTB_3rd \\
\hline P6 & $\mathrm{F} 81+\mathrm{G}$ & 130 & ATP8_1st, ATP8_2nd \\
\hline P7 & $\mathrm{GTR}+\mathrm{I}+\mathrm{G}$ & 522 & COX1_1st \\
\hline P8 & $\mathrm{GTR}+\mathrm{I}+\mathrm{G}$ & 511 & $C O X 3 \_1 \mathrm{st}, C O X 2 \_1 \mathrm{st}$ \\
\hline P9 & $\mathrm{GTR}+\mathrm{I}+\mathrm{G}$ & 906 & $N D 4 L \_1 \mathrm{st}, N D 4 \_1 \mathrm{st}, N D 1 \_1 \mathrm{st}$ \\
\hline $\mathrm{P} 10$ & $\mathrm{GTR}+\mathrm{I}+\mathrm{G}$ & 906 & $N D 4 \_2 \mathrm{nd}, N D 1 \_2 \mathrm{nd}, N D 4 L \_2 \mathrm{nd}$ \\
\hline P11 & $\mathrm{GTR}+\mathrm{G}$ & 906 & $N D 1 \_3 \mathrm{rd}, N D 4 \_3 \mathrm{rd}, N D 4 L \_3 \mathrm{rd}$ \\
\hline $\mathrm{P} 12$ & $\mathrm{GTR}+\mathrm{I}+\mathrm{G}$ & 599 & ND6_1st, ND2_1st \\
\hline $\mathrm{P} 13$ & $\mathrm{GTR}+\mathrm{I}+\mathrm{G}$ & 599 & ND6_2nd, ND2_2nd \\
\hline P14 & $\mathrm{GTR}+\mathrm{G}$ & 599 & ND6_3rd, ND2_3rd \\
\hline P15 & $\mathrm{GTR}+\mathrm{G}$ & 604 & ND5_1st \\
\hline P16 & $\mathrm{GTR}+\mathrm{G}$ & 604 & ND5_2nd \\
\hline P17 & $\mathrm{HKY}+\mathrm{G}$ & 603 & ND5_3rd \\
\hline
\end{tabular}


Table 4 (on next page)

Mitochondrial genome characteristics of $L$. sinicus. 


\begin{tabular}{|c|c|c|c|c|c|c|c|c|}
\hline Gene & Strand & Start & Stop & Length(bp) & $\begin{array}{c}\text { Start } \\
\text { codon }\end{array}$ & $\begin{array}{l}\text { Stop } \\
\text { codon }\end{array}$ & Anticodon & IGN \\
\hline trnI & $\mathrm{J}$ & 1 & 67 & 67 & & & GAU & 1 \\
\hline ND2 & $\mathrm{J}$ & 70 & 1113 & 1044 & ATG & TAA & & 2 \\
\hline $\operatorname{trn} W$ & $\mathrm{~J}$ & 1117 & 1181 & 65 & & & UCA & 3 \\
\hline COI & $\mathrm{J}$ & 1182 & 2720 & 1539 & ATT & TAA & & 0 \\
\hline $\operatorname{trn} L 2$ & $\mathrm{~J}$ & 2760 & 2825 & 66 & & & UAA & 39 \\
\hline COII & $\mathrm{J}$ & 2827 & 3510 & 684 & ATG & TAA & & 1 \\
\hline $\operatorname{trnK}$ & $\mathrm{J}$ & 3532 & 3602 & 71 & & & CUU & 21 \\
\hline $\operatorname{trn} D$ & $\mathrm{~J}$ & 3603 & 3672 & 70 & & & GUC & 0 \\
\hline ATP8 & $\mathrm{J}$ & 3673 & 3834 & 162 & ATC & TAA & & 0 \\
\hline ATP6 & $\mathrm{J}$ & 3828 & 4517 & 690 & ATG & TAA & & -7 \\
\hline COIII & $\mathrm{J}$ & 4504 & 5289 & 786 & ATG & TAA & & -14 \\
\hline $\operatorname{trn} G$ & $\mathrm{~J}$ & 5310 & 5373 & 64 & & & UCC & 20 \\
\hline$N D 3$ & $\mathrm{~J}$ & 5374 & 5724 & 351 & ATT & TAA & & 0 \\
\hline $\operatorname{trn} A$ & $\mathrm{~J}$ & 5732 & 5797 & 66 & & $\mathrm{~T}$ & UGC & 7 \\
\hline $\operatorname{trnR}$ & $\mathrm{J}$ & 5798 & 5,864 & 67 & & & UCG & 0 \\
\hline $\operatorname{trn} N$ & $\mathrm{~J}$ & 5,866 & 5,934 & 69 & & & GUU & 1 \\
\hline $\operatorname{trn} S 1$ & $\mathrm{~J}$ & 5,935 & 6,002 & 68 & & & UGA & 0 \\
\hline $\operatorname{trn} E$ & $\mathrm{~J}$ & 6,010 & 6,076 & 67 & & & UUC & 7 \\
\hline $\operatorname{trnF}$ & $\mathrm{N}$ & 6,092 & 6158 & 67 & & & $\mathrm{AAG}$ & 15 \\
\hline ND5 & $\mathrm{N}$ & 6,159 & 7872 & 1714 & ATT & $\mathrm{T}$ & & 0 \\
\hline $\operatorname{trn} H$ & $\mathrm{~N}$ & 7873 & 7940 & 68 & & & GUG & 0 \\
\hline ND4 & $\mathrm{N}$ & 7991 & 9343 & 1353 & ATT & TAA & & 50 \\
\hline$N D 4 L$ & $\mathrm{~N}$ & 9337 & 9618 & 282 & ATT & TAA & & -7 \\
\hline $\operatorname{trn} T$ & $\mathrm{~N}$ & 9621 & 9865 & 65 & & & UGU & 2 \\
\hline $\operatorname{trn} P$ & $\mathrm{~N}$ & 9686 & 9751 & 66 & & & GGU & 0 \\
\hline ND6 & $\mathrm{J}$ & 9753 & 10256 & 504 & ATA & TAA & & 1 \\
\hline CYTB & $\mathrm{J}$ & 10258 & 11391 & 1134 & ATA & TAA & & 1 \\
\hline $\operatorname{trn} S 2$ & $\mathrm{~J}$ & 11435 & 11502 & 68 & & & UCU & 43 \\
\hline ND1 & $\mathrm{N}$ & 11512 & 12462 & 951 & ATT & TAA & & 9 \\
\hline $\operatorname{trnL1}$ & $\mathrm{N}$ & 12463 & 12530 & 68 & & & GAU & 0 \\
\hline$r r n L$ & $\mathrm{~N}$ & 12531 & 13871 & 1341 & & & & 0 \\
\hline $\operatorname{trn} V$ & $\mathrm{~N}$ & 13872 & 13941 & 70 & & & CAU & 0 \\
\hline$r r n S$ & $\mathrm{~N}$ & 13941 & 14731 & 791 & & & & -1 \\
\hline
\end{tabular}




\begin{tabular}{|c|c|c|c|c|c|c|}
\hline $\operatorname{trn} M$ & $\mathrm{~J}$ & 14777 & 14845 & 69 & CAU & 45 \\
\hline $\operatorname{trn} Q$ & $\mathrm{~N}$ & 14843 & 14911 & 69 & GUU & -3 \\
\hline $\begin{array}{l}\text { AT-rich } \\
\text { region }\end{array}$ & none & 14912 & 15261 & 350 & & 0 \\
\hline $\operatorname{trn} Y$ & $\mathrm{~J}$ & 15262 & 15331 & 70 & GUA & 0 \\
\hline $\operatorname{trn} C$ & $\mathrm{~N}$ & 15333 & 15403 & 71 & ACG & 1 \\
\hline
\end{tabular}




\section{Table 5 (on next page)}

Nucleotide composition of $L$. sinicus mitochondrial genome. 
1

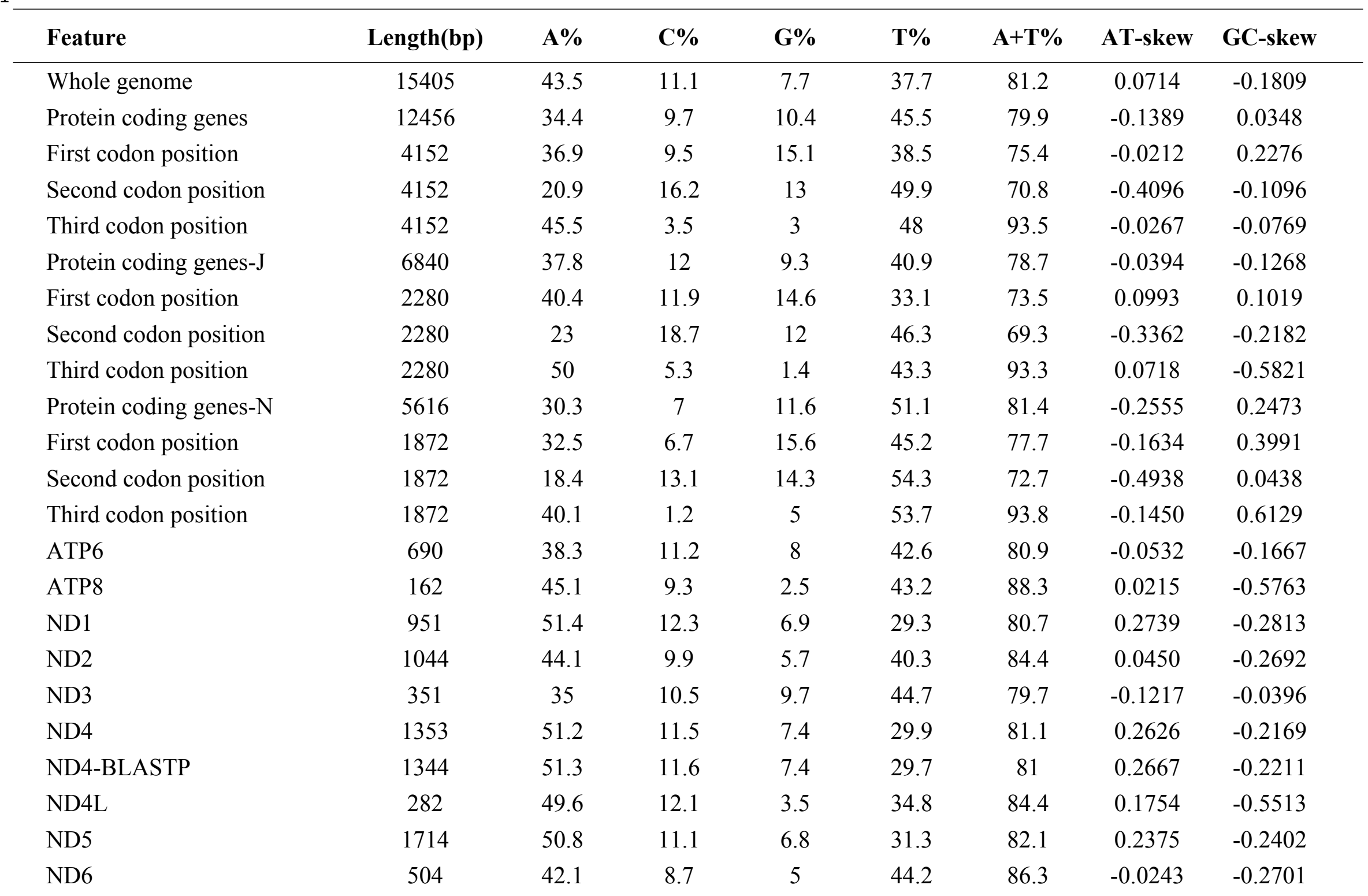




\begin{tabular}{lcccccccc} 
COI & 1539 & 35.1 & 13.5 & 12.8 & 38.7 & 73.8 & -0.0488 & -0.0266 \\
COII & 684 & 40.8 & 12.7 & 8 & 38.5 & 79.3 & 0.0290 & -0.2271 \\
COIII & 786 & 33.5 & 13 & 12 & 41.6 & 75.1 & -0.1079 & -0.0400 \\
CYTB & 1134 & 35.4 & 13.1 & 10.4 & 41.2 & 76.6 & -0.0757 & -0.1149 \\
$12 \mathrm{~s}$ & 791 & 44 & 10.7 & 5.3 & 40.1 & 84.1 & 0.04637337 & 0.3375 \\
$16 \mathrm{~s}$ & 1341 & 46.8 & 11 & 4.9 & 37.4 & 84.2 & 0.111639 & -0.383648 \\
\hline
\end{tabular}


Table 6 (on next page)

Codon usage of PCGs in mitochondrial genome of $L$. sinicus. No., frequency of each codon; RSCU, relative synonymous condon usage. 
1

\begin{tabular}{|c|c|c|c|c|c|c|c|c|c|}
\hline Amino acid & Codon & NO. & RSCU & & Amino acid & Codon & NO. & RSCU & \\
\hline \multirow[t]{2}{*}{ Phe } & TTT & 409 & 1.9 & & Tyr & TAT & 159 & 1.78 & \\
\hline & TTC & 21 & 0.1 & 2 & & $\mathrm{TAC}$ & 20 & 0.22 & 2 \\
\hline \multirow[t]{2}{*}{ Leu } & TTA & 560 & 5.04 & & End & TAA & 0 & 0 & \\
\hline & TTG & 35 & 0.31 & 5.35 & & TAG & 0 & 0 & \\
\hline \multirow[t]{4}{*}{ Leu } & CTT & 37 & 0.33 & & His & CAT & 68 & 1.79 & \\
\hline & CTC & 0 & 0 & & & $\mathrm{CAC}$ & 8 & 0.21 & 2 \\
\hline & CTA & 34 & 0.31 & 6 & Gln & CAA & 61 & 1.85 & \\
\hline & CTG & 1 & 0.01 & 0.65 & & $\mathrm{CAG}$ & 5 & 0.15 & 2 \\
\hline \multirow[t]{2}{*}{ Ile } & ATT & 464 & 1.87 & & Asn & AAT & 237 & 1.84 & \\
\hline & ATC & 31 & 0.13 & 2 & & $\mathrm{AAC}$ & 20 & 0.16 & 2 \\
\hline \multirow[t]{2}{*}{ Met } & ATA & 314 & 1.91 & & Lys & AAA & 135 & 1.88 & \\
\hline & ATG & 15 & 0.09 & 2 & & $\mathrm{AAG}$ & 9 & 0.13 & 2.01 \\
\hline \multirow[t]{4}{*}{ Val } & GTT & 83 & 2.21 & & Asp & GAT & 62 & 1.82 & \\
\hline & GTC & 1 & 0.03 & & & GAC & 6 & 0.18 & 2 \\
\hline & GTA & 65 & 1.73 & & Glu & GAA & 72 & 1.85 & \\
\hline & GTG & 1 & 0.03 & 4 & & GAG & 6 & 0.15 & 2 \\
\hline \multirow[t]{4}{*}{ Ser } & $\mathrm{TCT}$ & 134 & 2.67 & & Cys & TGT & 37 & 1.95 & \\
\hline & $\mathrm{TCC}$ & 4 & 0.08 & & & TGC & 1 & 0.05 & 2 \\
\hline & TCA & 116 & 2.31 & & Trp & TGA & 92 & 1.8 & \\
\hline & $\mathrm{TCG}$ & 2 & 0.04 & 5.1 & & TGG & 10 & 0.2 & 2 \\
\hline \multirow[t]{2}{*}{ Pro } & $\mathrm{CCT}$ & 64 & 1.97 & & Arg & CGT & 20 & 1.54 & \\
\hline & $\mathrm{CCC}$ & 15 & 0.46 & & & CGC & 0 & 0 & \\
\hline
\end{tabular}




\begin{tabular}{cccccccccc} 
& CCA & 48 & 1.48 & & & CGA & 31 & 2.38 & \\
\multirow{4}{*}{ Thr } & CCG & 3 & 0.09 & 4 & & CGG & 1 & 0.08 & 4 \\
& ACT & 70 & 1.74 & & Ser & AGT & 23 & 0.46 & \\
& ACC & 8 & 0.2 & & & AGC & 1 & 0.02 & \\
& ACA & 82 & 2.04 & & & AGA & 119 & 2.37 & \\
\multirow{4}{*}{ Ala } & ACG & 1 & 0.02 & 4 & & AGG & 2 & 0.04 & 2.89 \\
& GCT & 65 & 2.08 & & Gly & GGT & 62 & 1.22 & \\
& GCC & 7 & 0.22 & & & GGC & 1 & 0.02 & \\
& GCA & 49 & 1.57 & & & GGA & 112 & 2.2 & \\
& GCG & 4 & 0.13 & 4 & & GGG & 29 & 0.57 & 4.01 \\
\hline
\end{tabular}


Figure 1

Labriocimbex sinicus Yan \& Wei sp. nov.

(A) Adult female (holotype), dorsal view; (B) Adult male (paratype), dorsal view. Scale bar $=2$ $\mathrm{mm}$. 

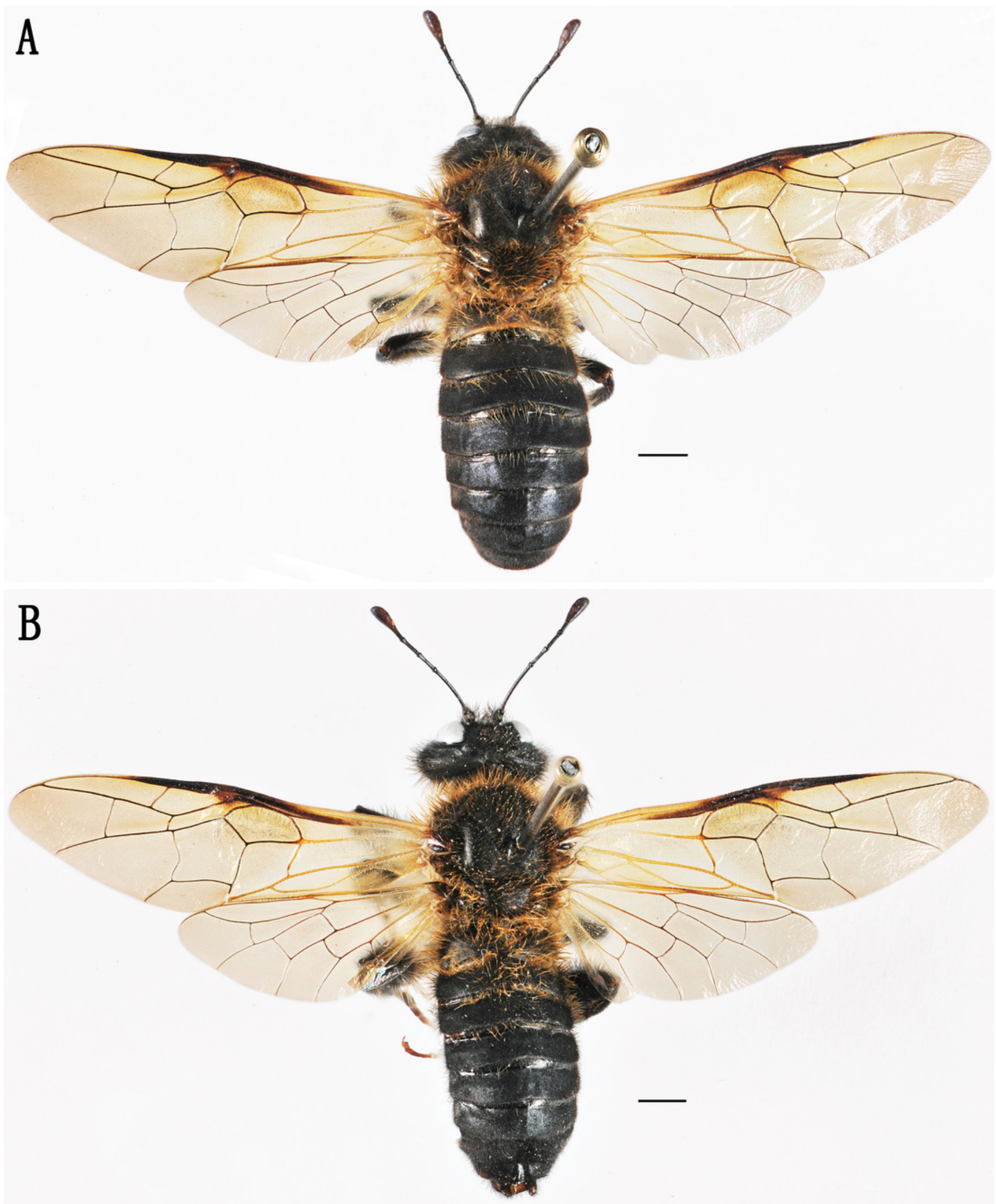
Figure 2

Labriocimbex sinicus Yan \& Wei, gen. et sp. nov.

(A) Head of female, front view; (B) Head of female, lateral view; (C) Mesopleuron of female, lateral view; (D) Head of female, dorsal view; (E) Metanotum and base of abdomen; (F) Abdomen, lateral view; (G) Palpus; (H) Antenna of female. 


\section{A}
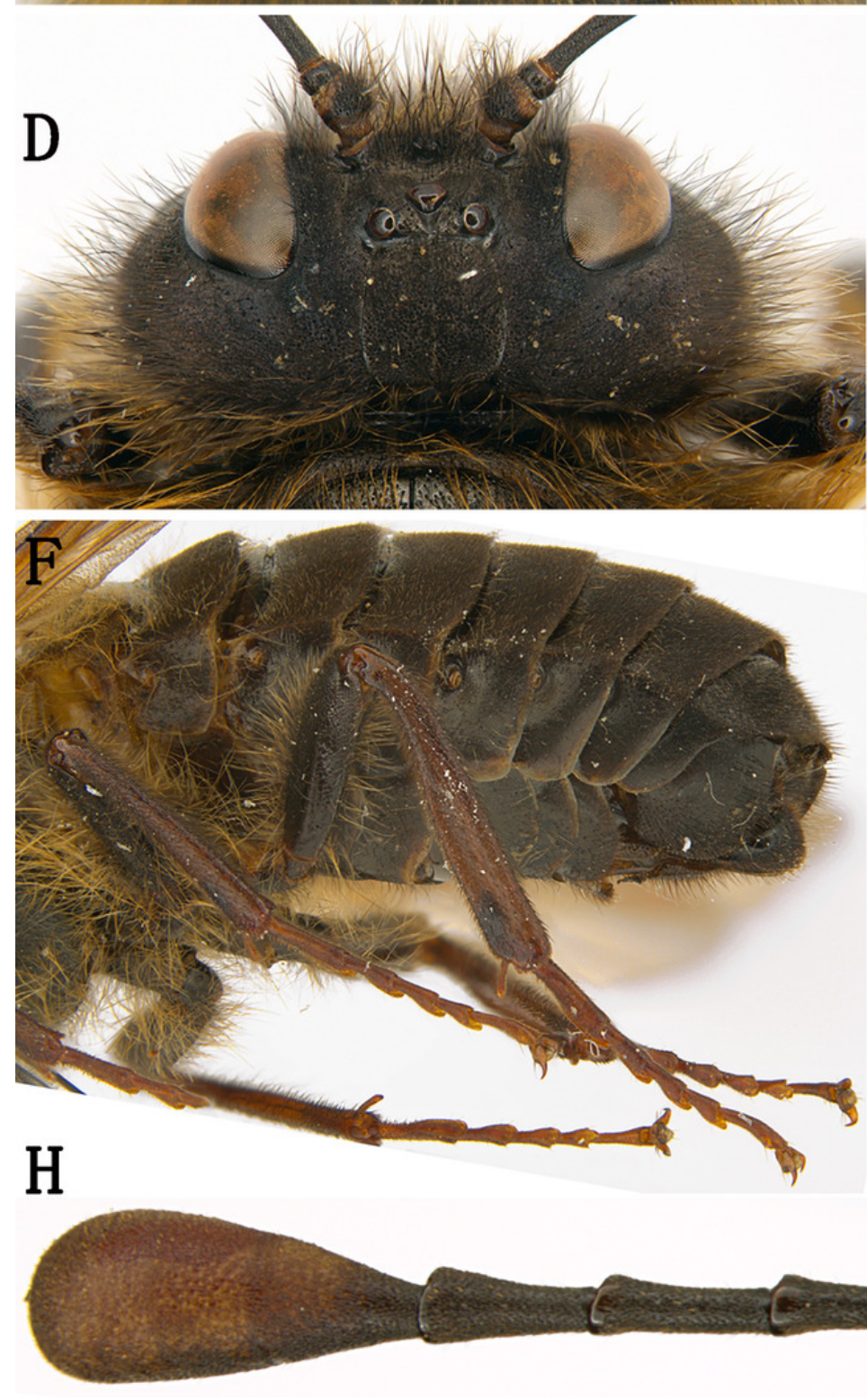

PeerJ reviewing PDF | (2019:01:34672:4:0:NEW 3 Sep 2019) 


\section{Figure 3}

Labriocimbex sinicus Yan \& Wei, gen. et sp. nov.

(A) Left mandible; (B) Right mandible; (C) Femur of hind leg; (D) Ovipositor sheath of female, lateral view; (E) Genital plate of male, ventral view; (F) Ovipositor sheath of female, dorsal view, (G) Middle serrulae, Scale bar = 50 um; (H) Penis valve; (I) Gonoforcep; (J) Spur of hind tibia; (K) Claw; (L) Apex of abdomen, ventral view; (M) Lance; (N) Lancet (H, I, M and N, Scale bar $=200 \mathrm{um})$. 

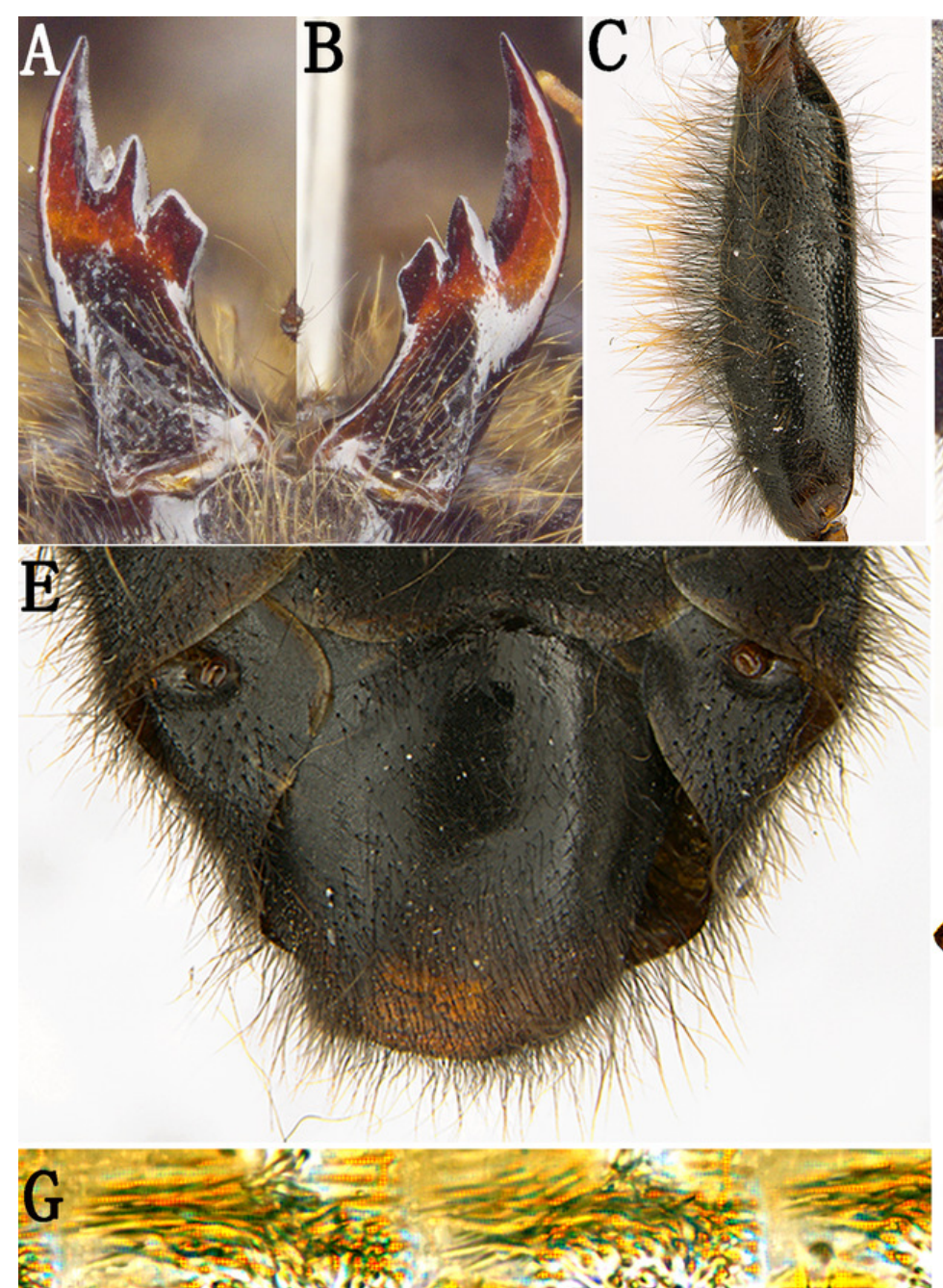

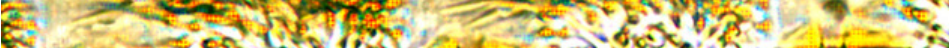

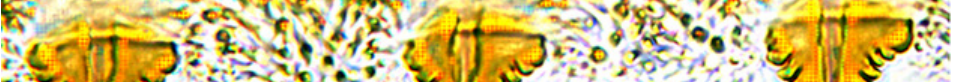
缘
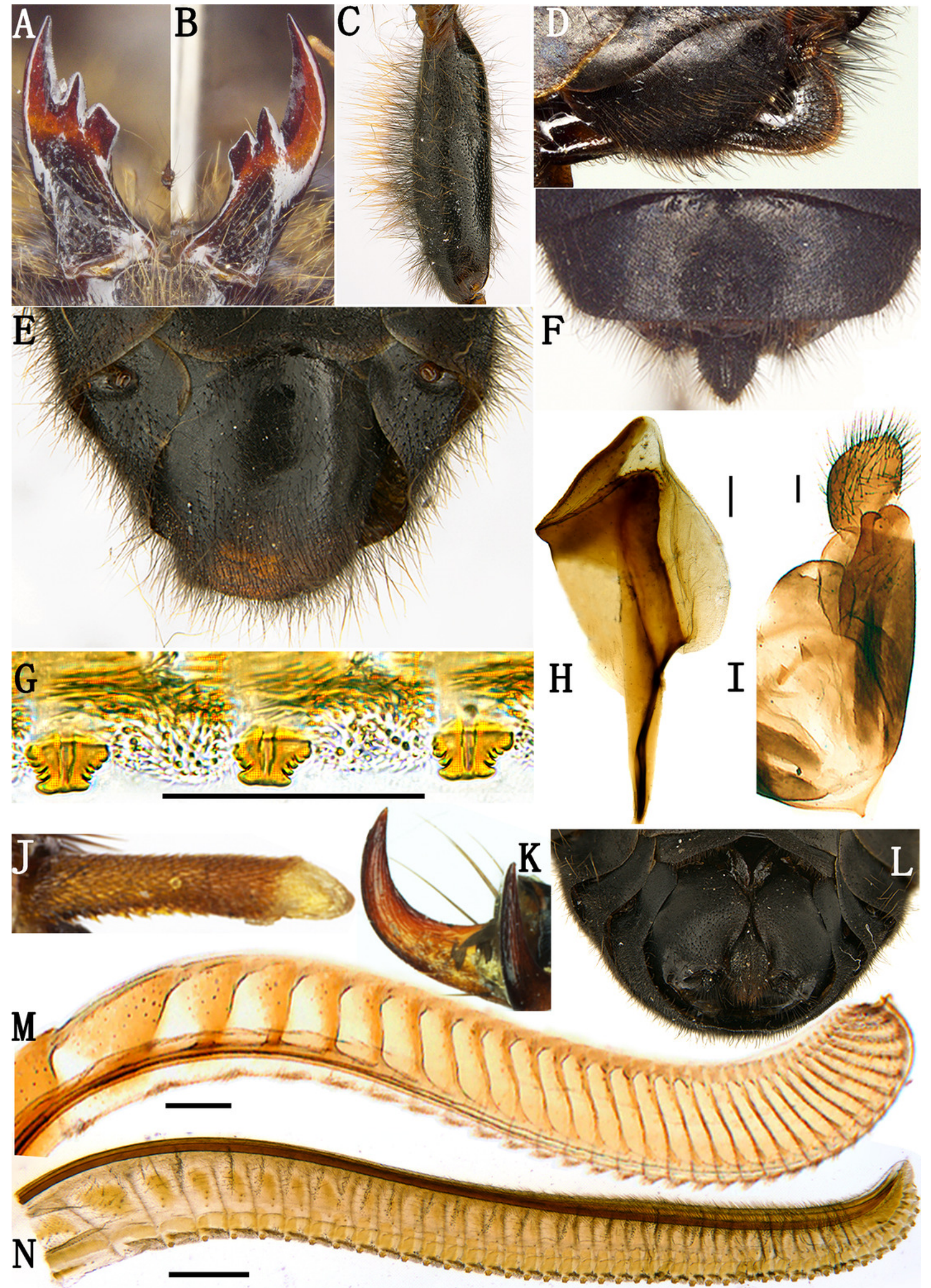
Figure 4

Labriocimbex zaraeoides (Malaise, 1939) comb. nov.

(A) Adult female (holotype), Scale bar $=2 \mathrm{~mm}$; (B) Mesopleuron of female, lateral view; (C) Head of female, front view; (D) Abdomen, lateral view; (E) Head of female, dorsal view; (F) Head of female, lateral view; $(G)$ Metanotum and basal of abdominal terga, dorsal view; $(H)$ Labels. 

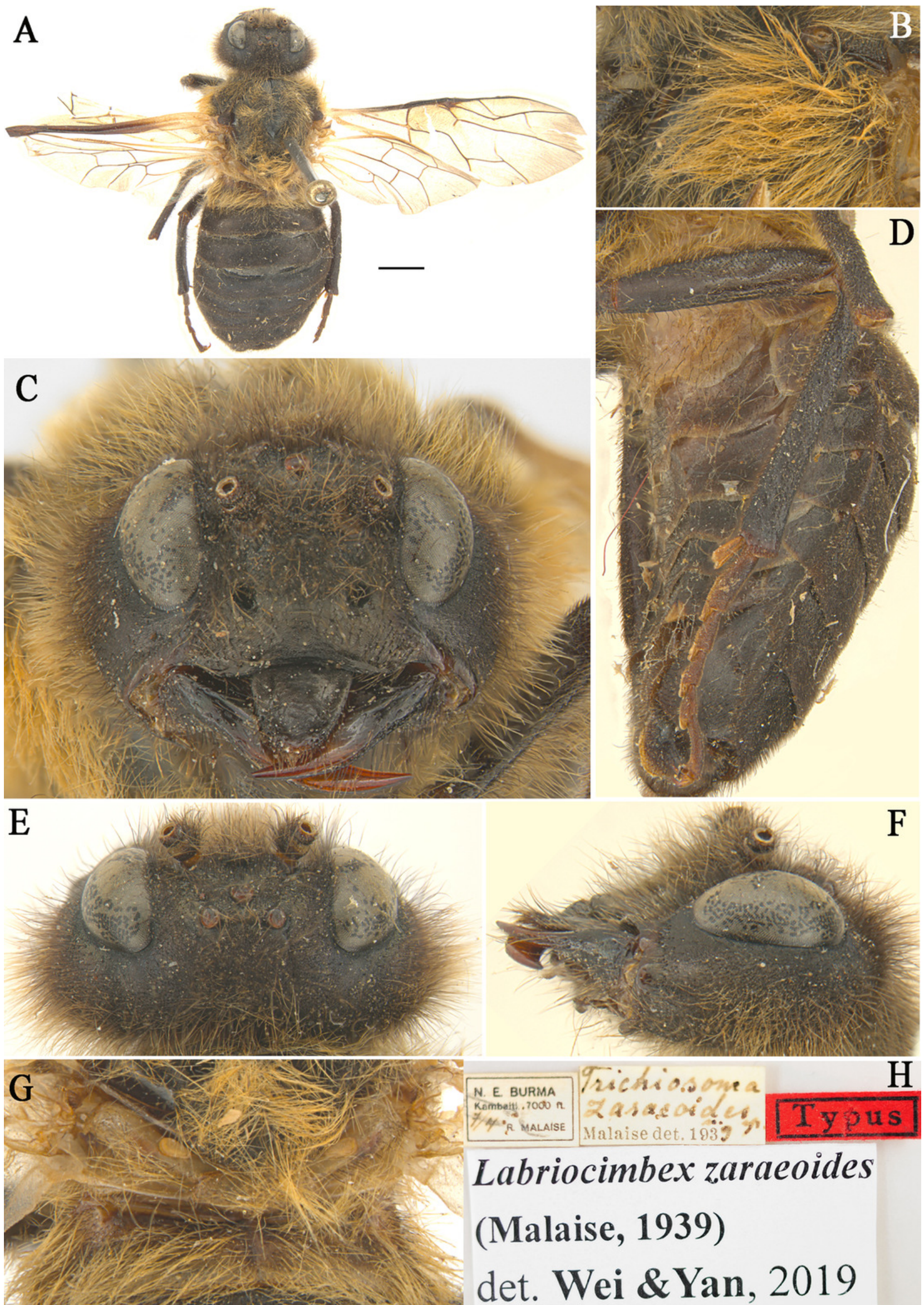

N.E BURMA $\frac{9}{2}$ ichis 0.4 orye

$\mathrm{H}$

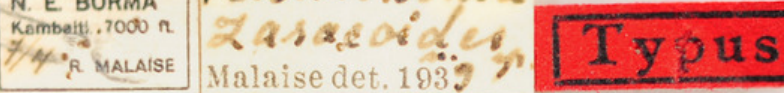

Labriocimbex zaraeoides

(Malaise, 1939)

det. Wei \&Yan, 2019

Peer) reviewing PDF | (2019:01:34672:4:0:NEW 3 Sep 2019) 


\section{Figure 5}

Mitochondrial genome organization of three cimbicid species referenced with the ancestral insect mitochondrial genomes.

Genes transcribed from the J and N strands are shown with green and orange color, respectively. Overlapping and intergenic regions are marked in yellow and blue circles. tRNA genes are denoted by a one-letter symbol according to the IPUC-IUB single-letter amino acid codes A+ T-rich region is marked in blue and tRNA genes are labelled by the single-letter amino acid code. (A) Ancestral type of insect mitochondrial genomes; (B) Corynis laterlis mitochondrial genomes; (C) Trichiosoma anthracinum mitochondrial genomes; (D) Labriocimbex sinca mitochondrial genomes.

Ancestral type

A

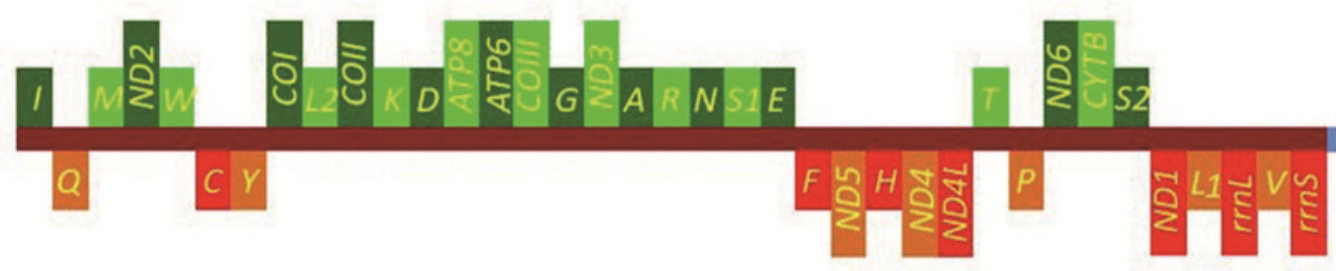

Corynis laterlis

B

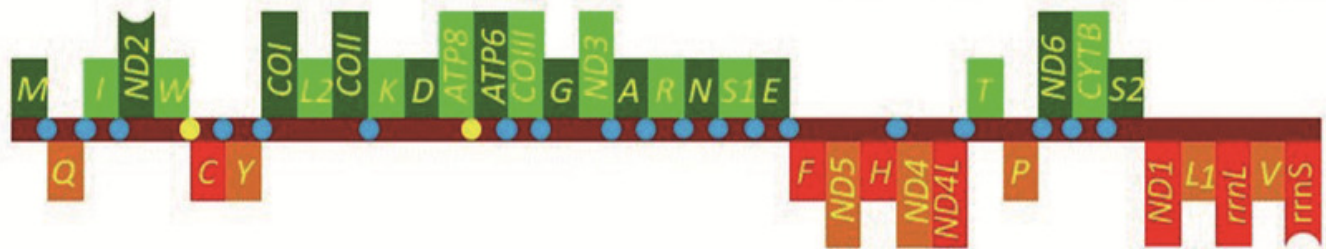

Trichiosoma anthracinum

$\mathrm{C}$
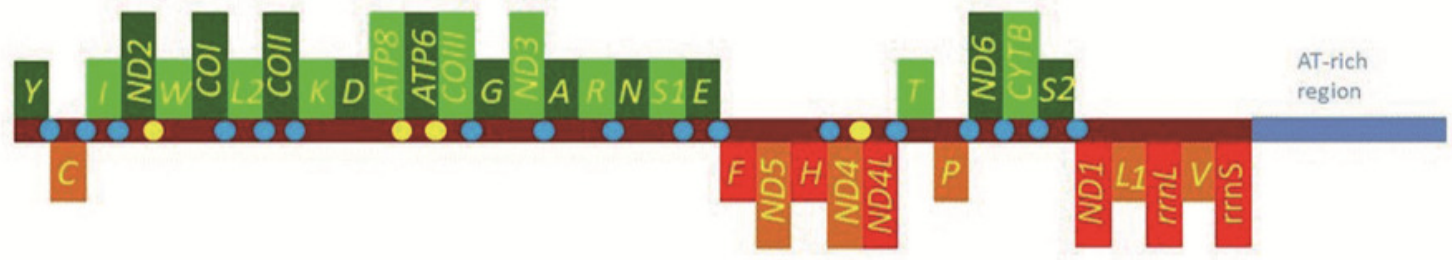

Labriocimbex sinica

$\mathrm{D}$

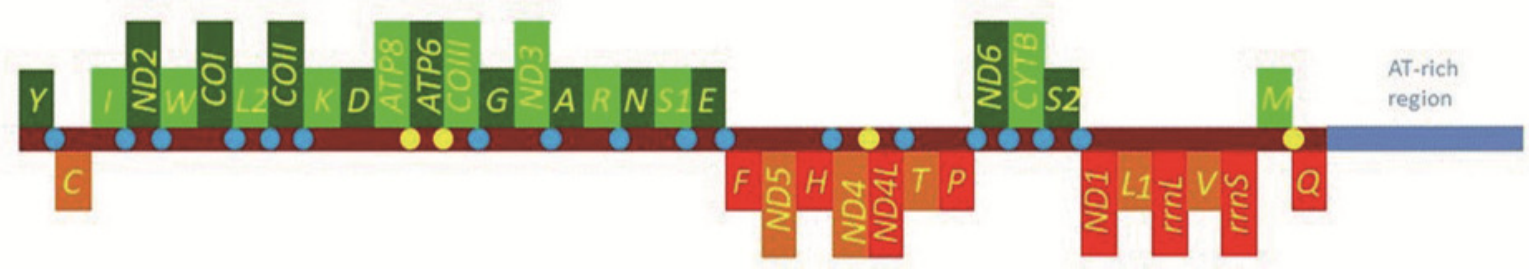




\section{Figure 6}

redicted secondary structures for the 22 typical tRNA genes of $L$. sinicus and $T$. anthracinum (adapted from Doğan and Korkmaz, 2017) mitogenomes.

Base-pairing is indicated as follows: Watson-Crick pairs by lines, wobble GU pairs by dots and other noncanonical pairs by circles. Variable regions are presented in boxes with red ( $L$. sinicus) and blue (T. anthracinum) color . (A) trnA; (B) trnR; (C) trnN; (D) trnD; (E) trnC; (F) trnQ; (G) trnE; (H) trnG; (I) trnH; (J) trnl; (K) trnL1; (L) trnL2; (M) trnK; (N) trnM; (O) trnF; (P) $\operatorname{trnP}$; (Q) trnS1; (R) trnS2; (S) trnT; (T) trnW; (U) trnY; (V) trnV. 

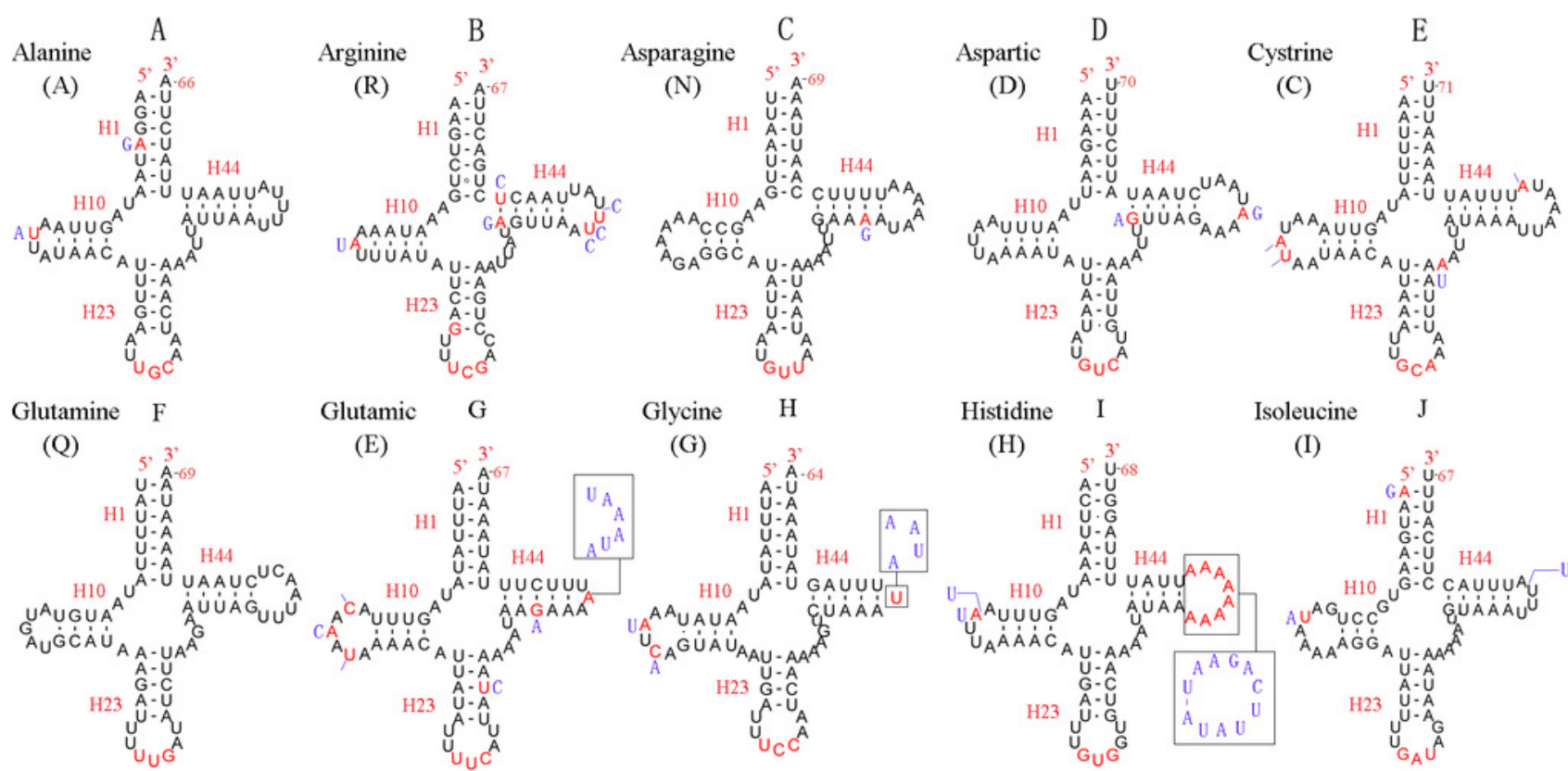

Glutamic G

Glycine $\quad H$

(E) $\quad, 3, \quad$ (G)

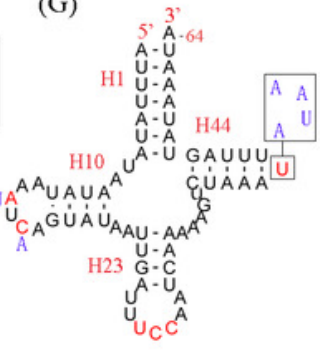

Histidine I

(H)

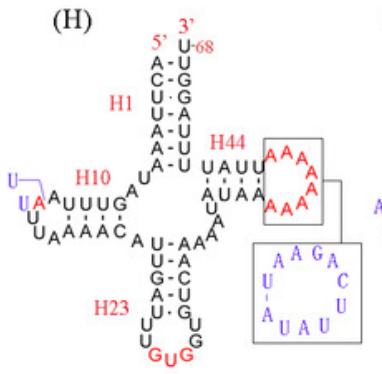

soleucine $\mathrm{J}$

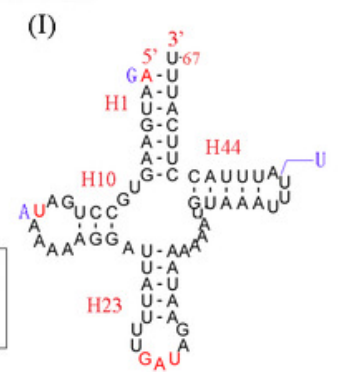

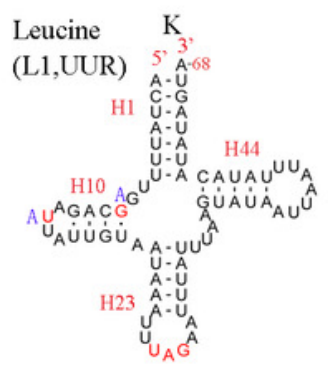
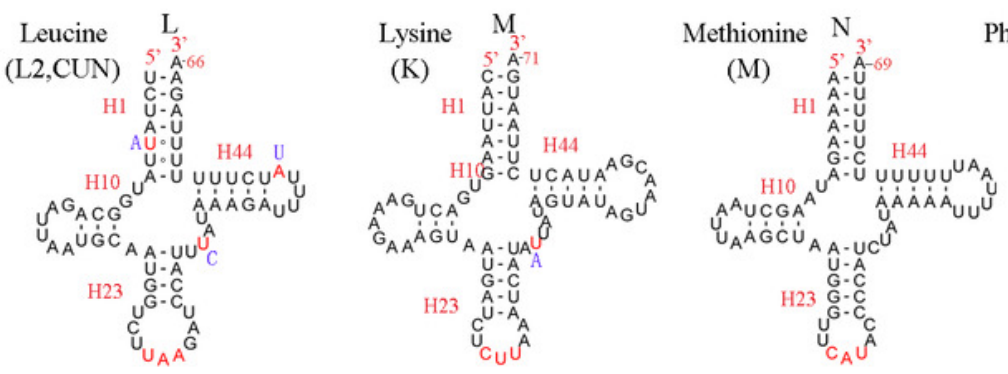

Phenylalanine $\mathrm{O}_{3}$,
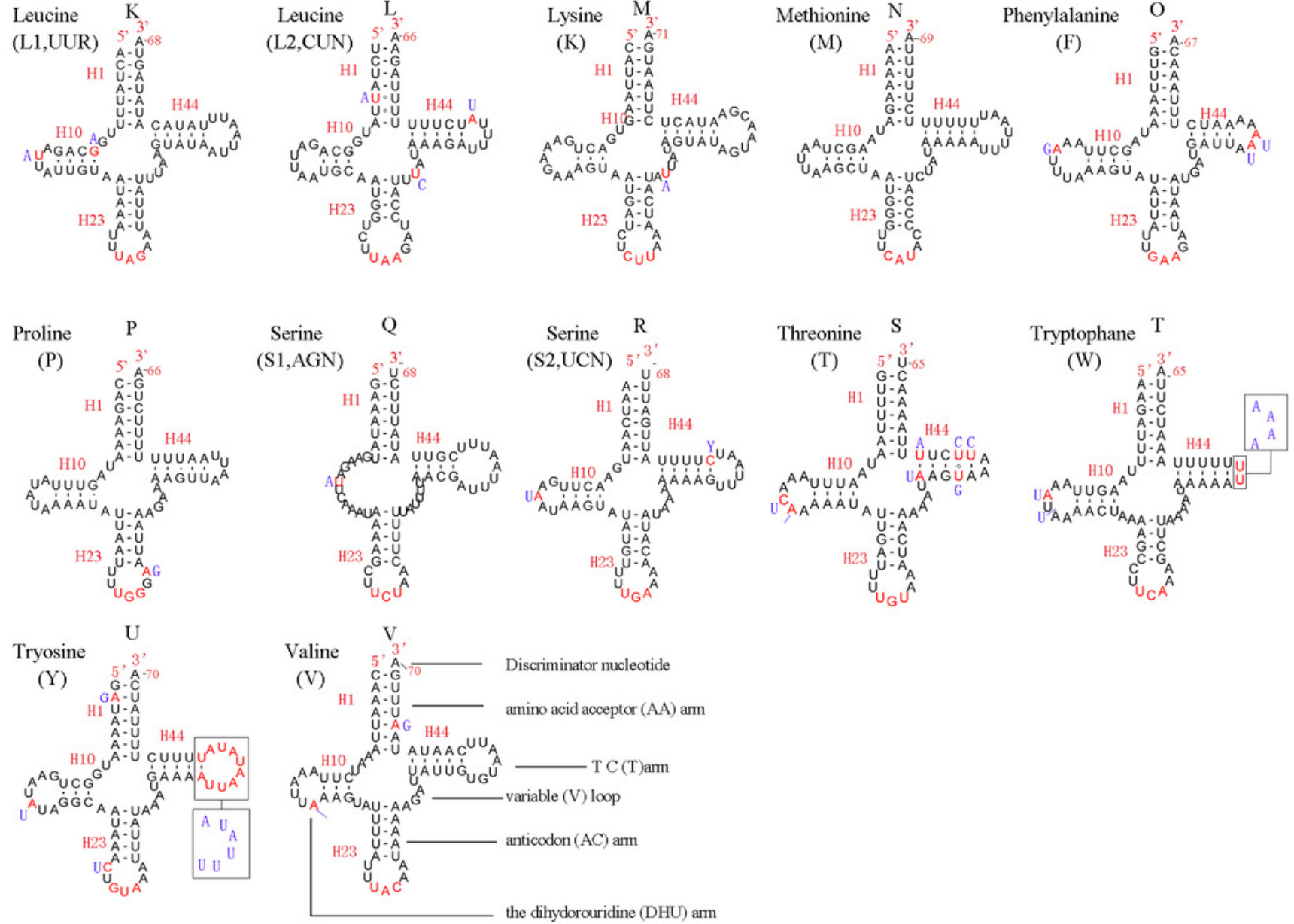


\section{Figure 7}

Predicted secondary structures for the 22 tRNA genes of C. lateralis (adapted from Song et al., 2016).

Dashes indicate Watson-Crick base pairing and dots indicate G-U base pairing. (A) $\operatorname{trnA}$; (B) trnR; (C) trnN; (D) trnD; (E) trnC; (F) trnQ; (G) trnE; (H) trnG; (I) trnH; (J) trnl; (K) trnLI; (L) trnL2; (M) trnK; (N) trnM; (O) trnF; (P) trnP; (Q) trnS1; (R) trnS2; (S) trnT; (T) trnW; (U) trnY; (V) trnV. 


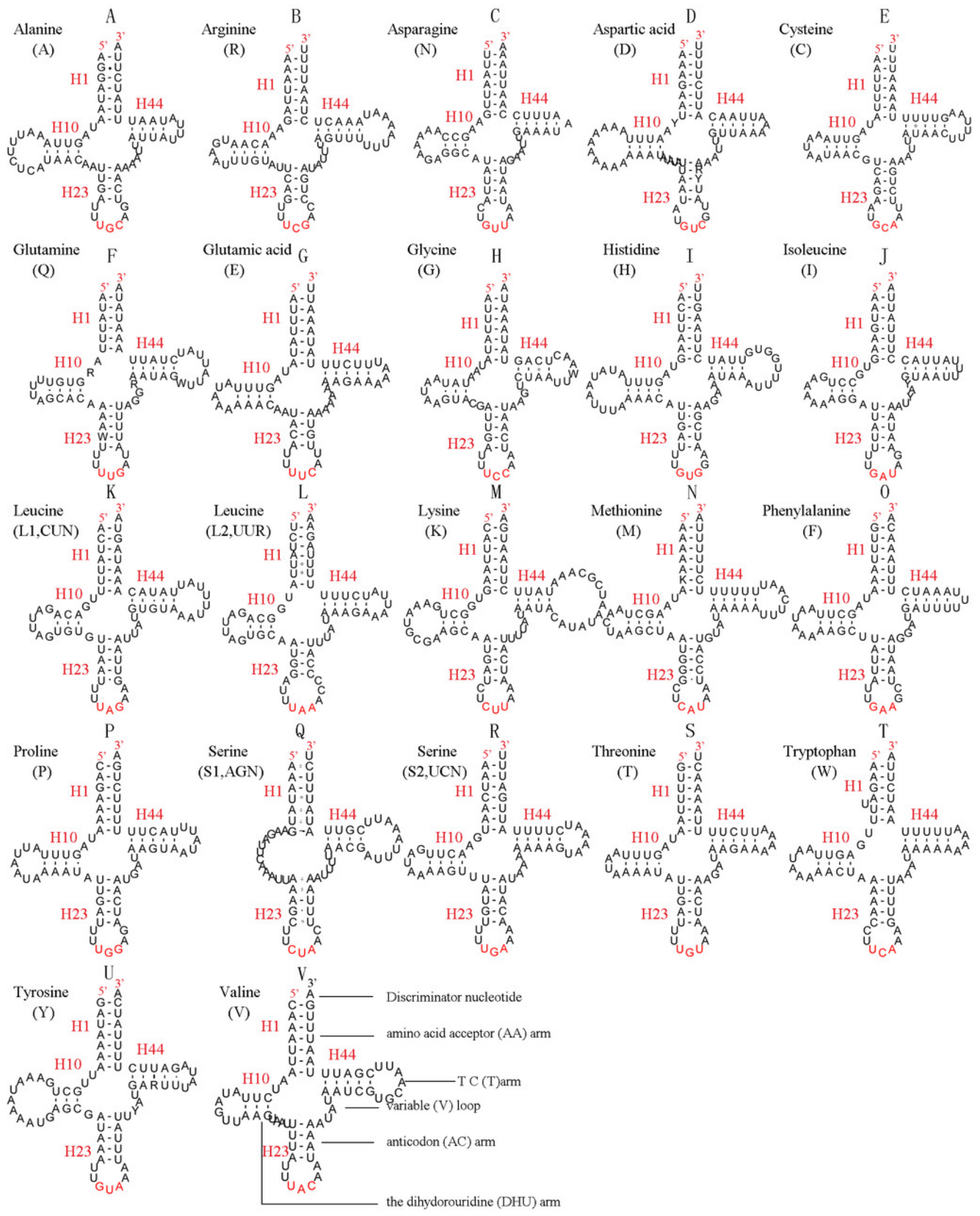




\section{Figure 8}

The predicted secondary structures of $r r n L$ of $L$. sinicus and $T$. anthracinum.

Tertiary interactions and base triples are connected by continuous lines. The numbering of helix follows Gillespie et al. (2006). Roman numbers refer to domain names. Dashes indicate Watson-Crick base pairing and dots indicate G-U base pairing. The helical variation among cimbicid species are presented in boxes with red (L. sinicus) and blue ( $T$. Anthracinum) color.

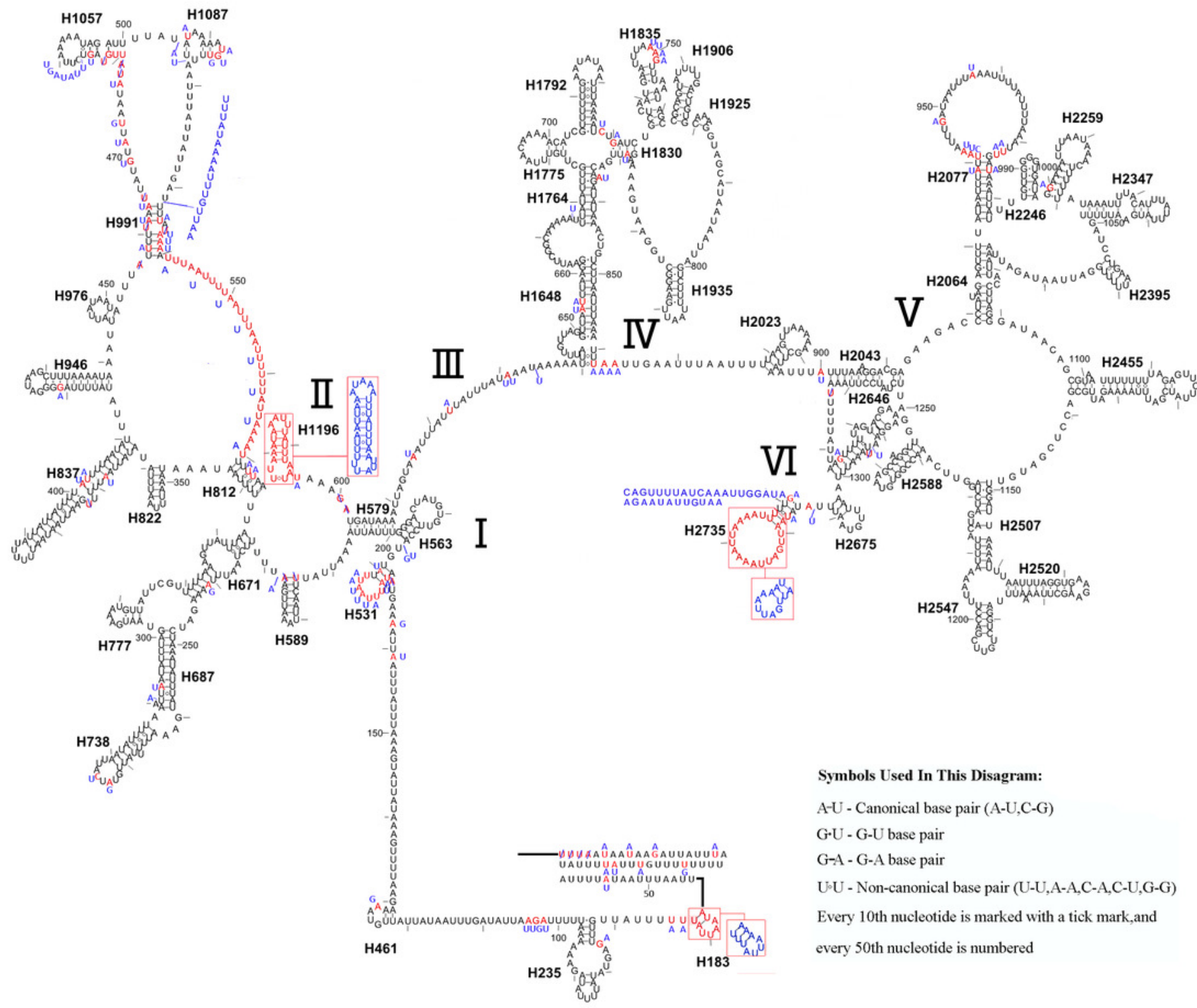


Figure 9

Corynis lateralis $r r n L$

Predicted $r r n L$ secondary structure in $C$. lateralis. The numbering of helix follows Gillespie et al. (2006).Roman numbers refer to domain names.

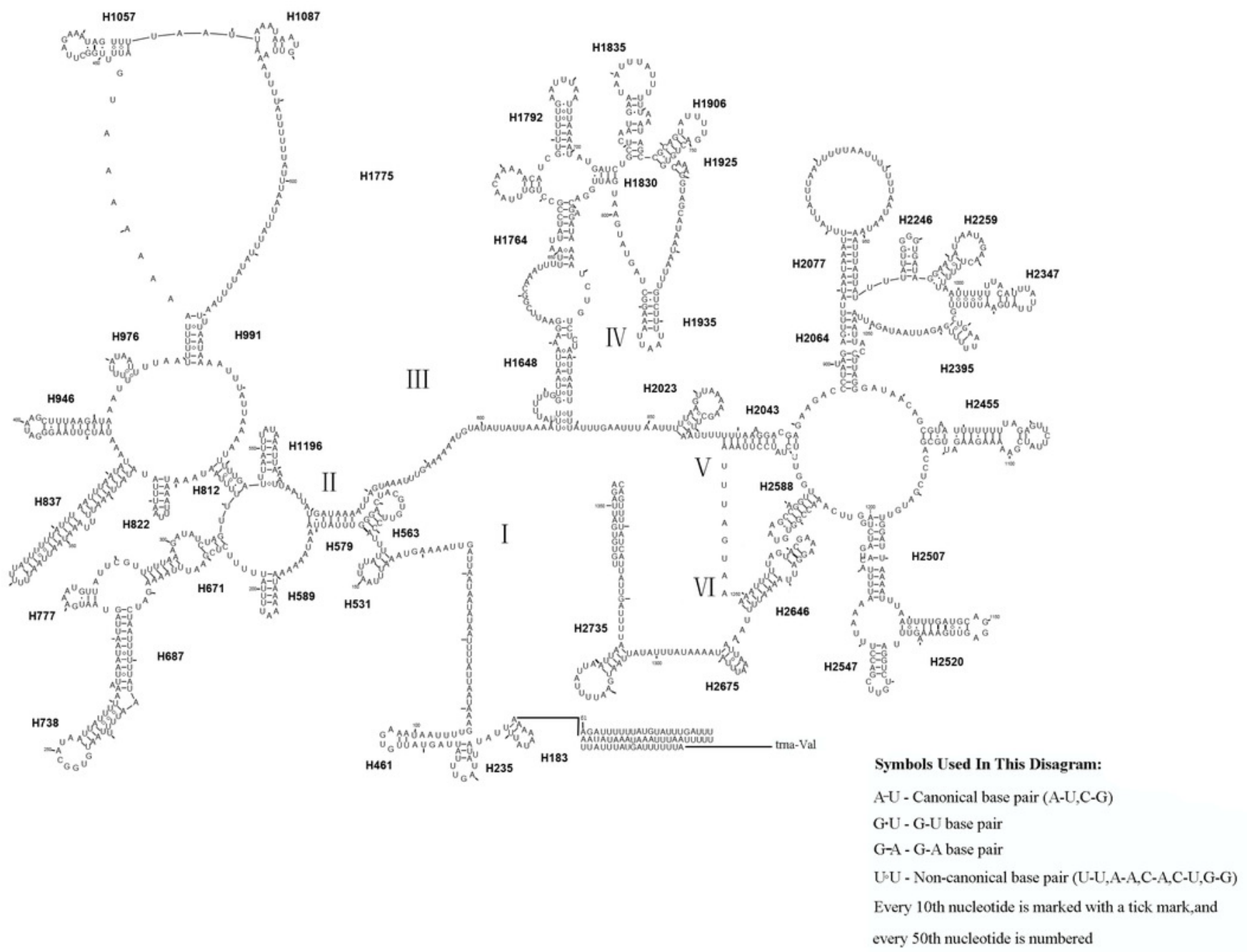




\section{Figure 10}

The predicted secondary structures of $r r n S$ of $L$. sinicus and $T$. anthracinum.

Tertiary interactions and base triples are connected by continuous lines. The numbering of helix follows Gillespie et al. (2006). Roman numbers refer to domain names. Dashes indicate Watson-Crick base pairing and dots indicate G-U base pairing. The helical variation among cimbicid species are presented in boxes with red (L. sinicus) and blue ( $T$. anthracinum) color. 


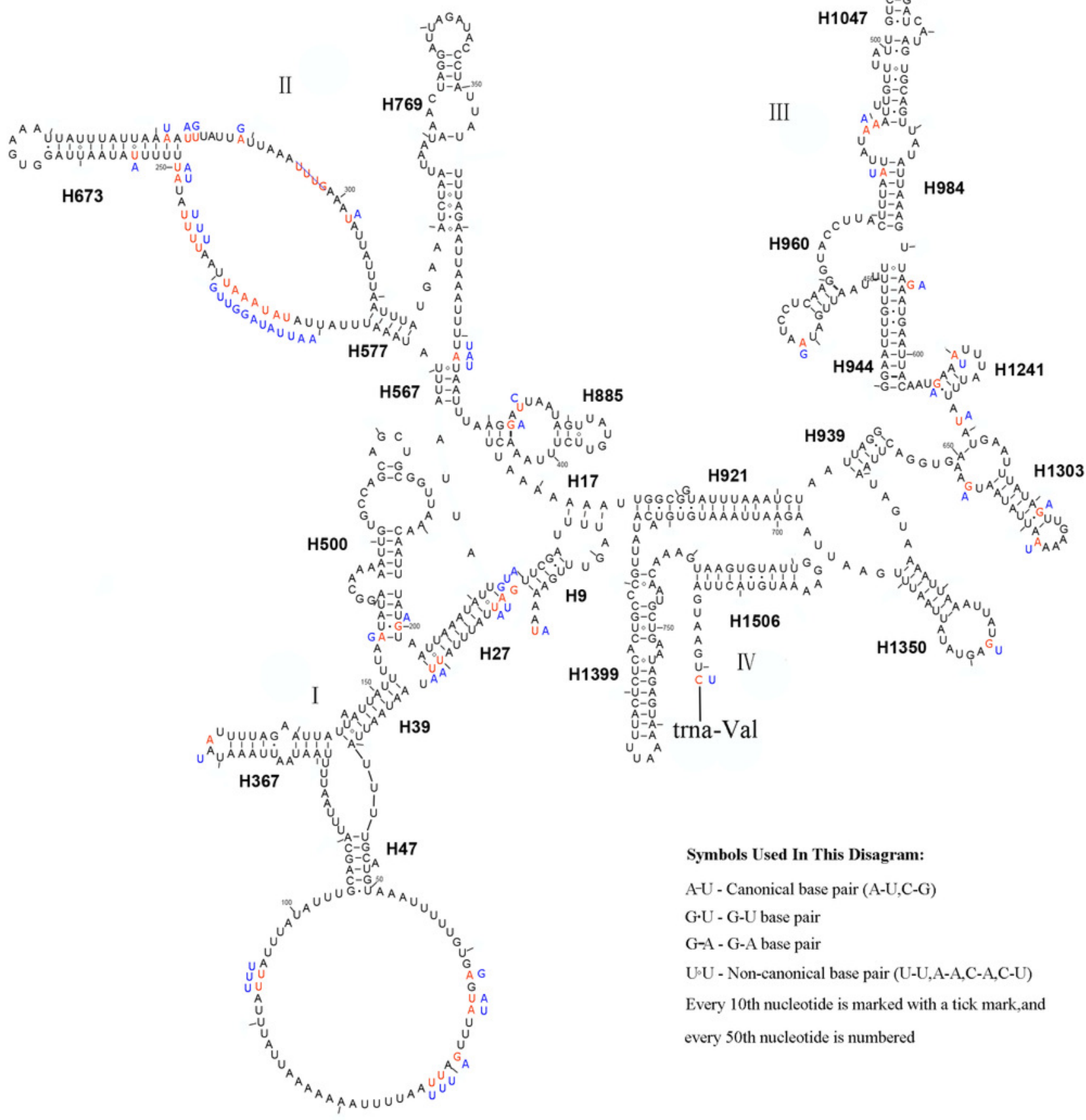


Figure 11

Corynis lateralis rrnS

Predicted rrnS secondary structure in C. lateralis. The numbering of helix follows Gillespie et al. (2006). Roman numbers refer to domain names. 

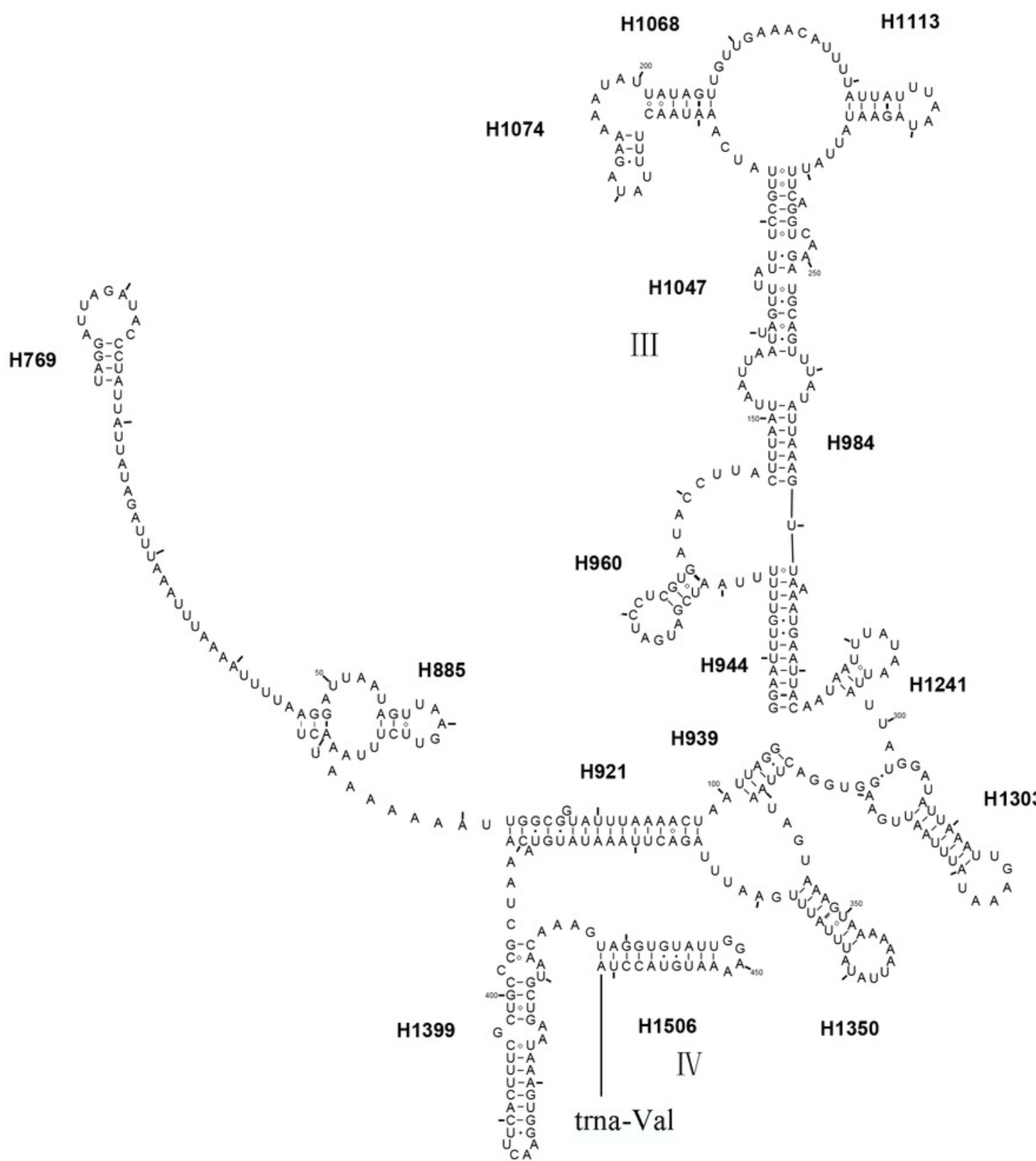

Symbols Used In This Disagram:

A-U - Canonical base pair (A-U,C-G)

G.U - G-U base pair

G-A - G-A base pair

$\mathrm{U} \cdot \mathrm{U}$ - Non-canonical base pair (U-U,A-A,C-A,C-U)

Every 10th nucleotide is marked with a tick mark,and every 50 th nucleotide is numbered 
Figure 12

Symphytan phylogenetic tree constructed with $\mathrm{BI}$ and $\mathrm{ML}$ approaches using a mitochondrial genome dataset including 15 individual genes (13 PCGs and two rRNAs).

Both analyses produced the same tree topology. Support values lower than $100 \%$ in the ML analysis and 1.0 in the $\mathrm{BI}$ analysis were shown.

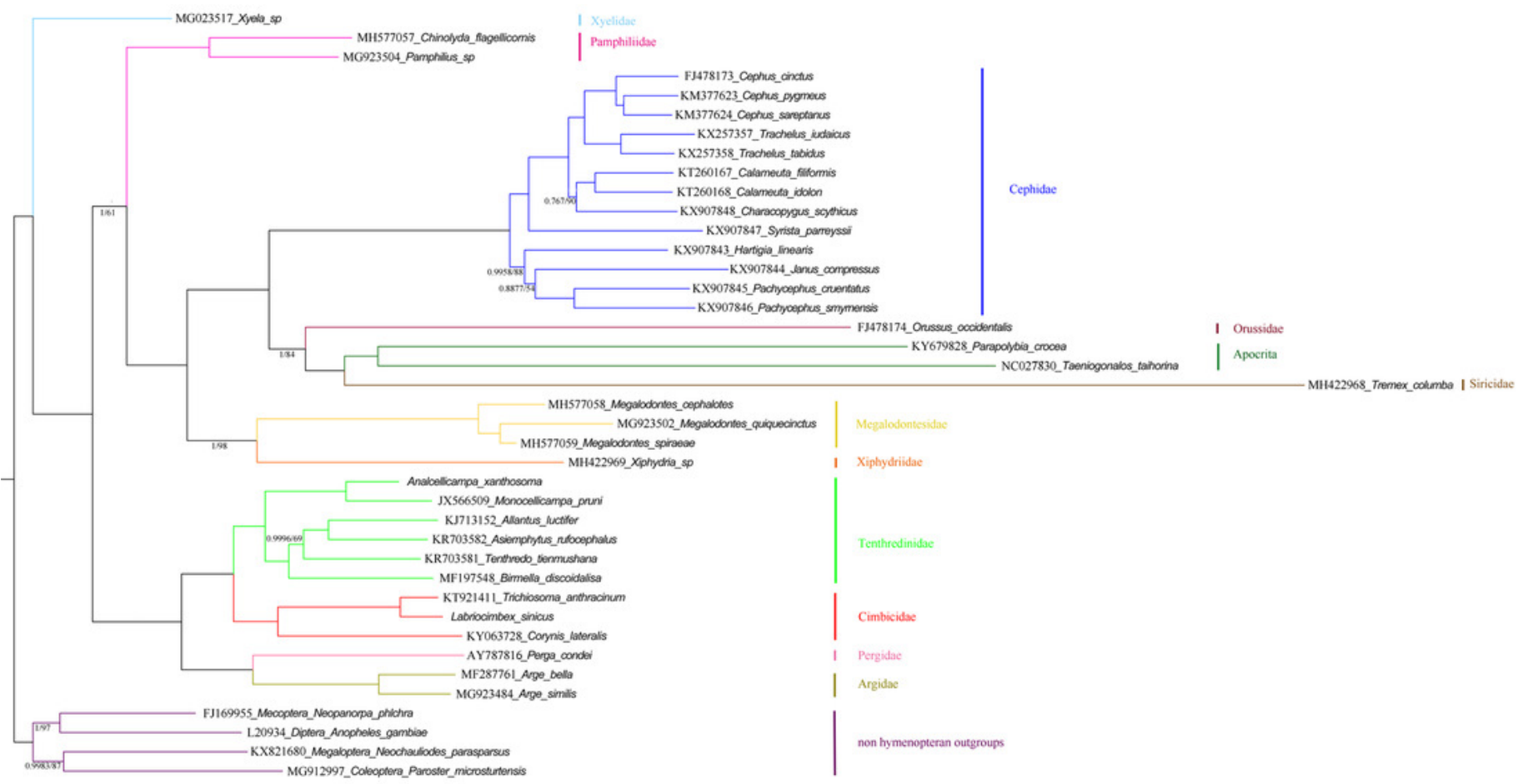


Figure 13

Cimbicidae phylogenetic tree constructed with $\mathrm{BI}$ and $\mathrm{ML}$ approaches using the $\mathrm{COI}$ gene data.

Both analyses produced the same tree topology. Support values lower than $100 \%$ in the ML analysis and 1.0 in the $\mathrm{BI}$ analysis were shown.

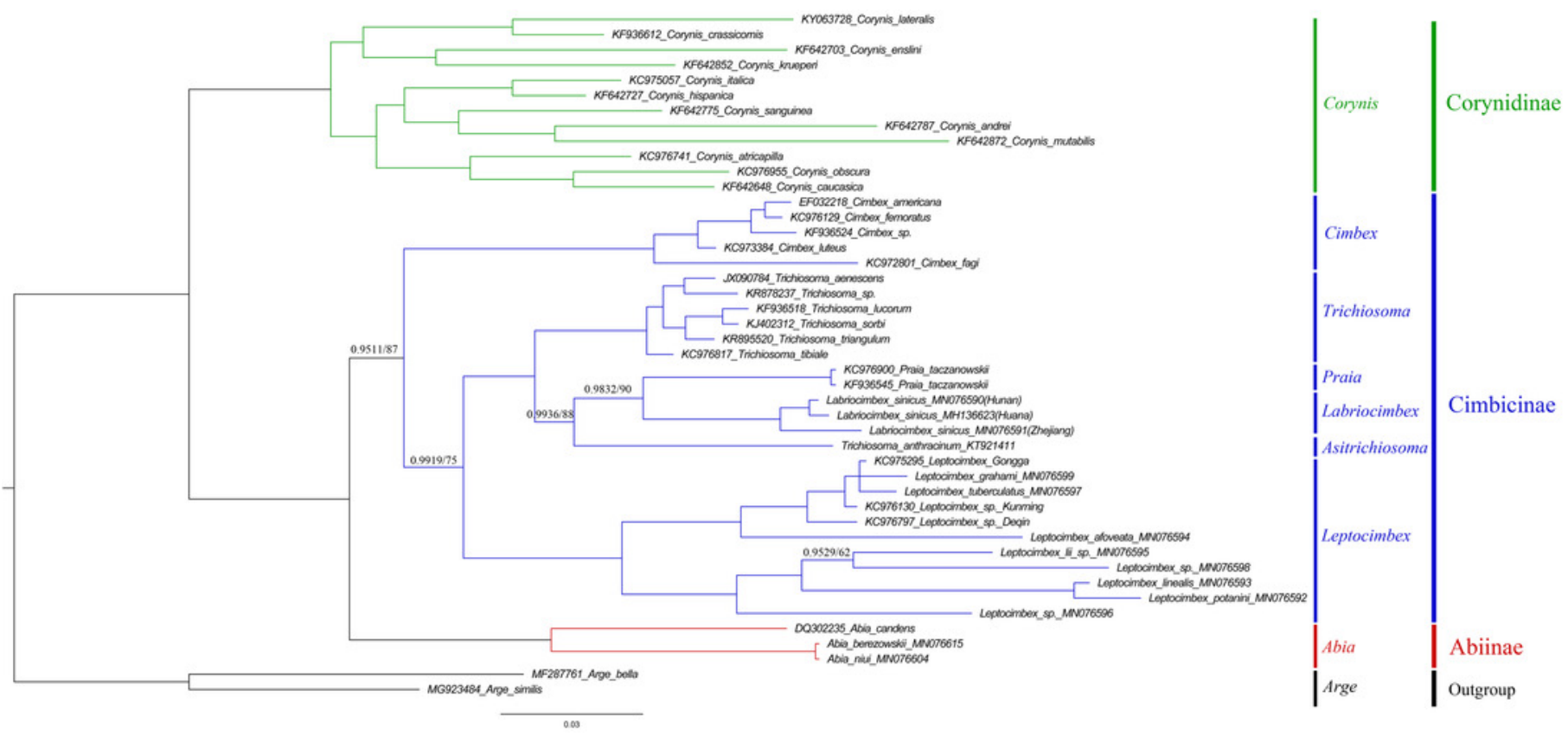

